\title{
Illocution and accommodation in the functioning of presumptions
}

\author{
Maciej Witek ${ }^{1}$ (I)
}

Received: 22 March 2019 / Accepted: 29 October 2019 / Published online: 9 November 2019

(c) The Author(s) 2019

\begin{abstract}
In this paper, I develop a speech-act based account of presumptions. Using a scorekeeping model of illocutionary games, I argue that presumptions construed as speech acts can be grouped into three illocutionary act types defined by reference to how they affect the state of a conversation. The paper is organized into two parts. In the first one, I present the score-keeping model of speech act dynamics; in particular, I distinguish between two types of mechanisms - the direct mechanism of illocution and the indirect one of accommodation - that underlie the functioning of illocutionary acts. In the second part, I use the presented model to distinguish between (1) the unilateral act of individual presumption, the point of which is to shift the burden of proof by making the hearer committed to justifying his refusal to endorse the proposition communicated by the speaker, whenever he refuses to endorse it, (2) the bilateral act of joint presumption- 'bilateral' in that it is performed jointly by at least two conversing agents - the function of which is to confer on the proposition endorsed by the speaker the normative status of jointly recognized though tentative acceptability, and (3) the indirect or back-door act of collective presumption, the purpose of which is to sustain rules and practices to which the conversing agents defer the felicity of their conversational moves.
\end{abstract}

Keywords Presumptions · Burden of proof $\cdot$ Speech acts $\cdot$ Score-keeping · Accommodation $\cdot$ Illocution

\section{Introduction}

My aim in this paper is to develop a speech act-based model of presumptions. It should be stressed from the outset, however, that the class of phenomena that argumentation

Maciej Witek

maciej.witek@usz.edu.pl

1 Institute of Philosophy and Cognitive Science, University of Szczecin, ul. Krakowska 71-79, 71-017 Szczecin, Poland 
theorists refer to and discuss as presumptions is not homogeneous. As Lewiński (2017) notes, it covers propositions and acts of their acceptance, claims and their discursive statuses, inferences and their conclusions, procedures and the decisions based on them, rules and the practices they govern, and so on. The central idea behind the proposed account is that at least some of the above-mentioned phenomena can be adequately understood and explained using a score-keeping model of illocutionary games (Witek 2015c), which results from integrating elements of Austin's (1975) theory of speech acts within the framework of Lewis's (1979) model of conversational kinematics. I also assume, following Walton (1993) and Corredor (2017), that to presume something is to make a conversational move understood as an illocutionary act, the force of which is to be characterised by reference to the way it modifies the distribution of the burden of proof among the participants in a dialogue.

In what follows, I assume that any candidate for an adequate theory of presumption is supposed to account for two characteristic properties of presumptions and meet four requirements that these characteristics give rise to. First, it is commonly agreed (Bermejo-Luque 2016; Corredor 2017; Godden 2017; Godden and Walton 2007; Lewiński 2017; Walton 1993) that presumptions occurring in the course of a critical discussion transfer the burden of proof from the proponent to the opponent. Therefore, it is reasonable to expect any valuable theory of presumptions to $(a)$ account for the dynamics of the distribution of the burden of proof among the conversing agents and $(b)$ specify the conditions under which presumptions - as well as the shifts of discursive obligations they bring about - are legitimate, correct, felicitous, or warranted. Second, it is widely held that presumptions have a characteristic pragmatic dimension; that is to say, they confer on some propositions put forth in a dialogue the defeasible status of jointly recognized acceptability, in virtue of which the propositions in question can be used as premises enabling discourse to proceed despite the absence of conclusive or sufficient evidence. We are, then, looking for a theoretical framework suited for $(c)$ modelling the dynamics of presumptive statuses and $(d)$ describing conditions that warrant our jointly-made decisions to proceed in argument as if certain propositions were true or justified.

My contention in this paper is that the score-keeping model of illocutionary games provides conceptual tools for developing an account of presumptions which satisfies the above-mentioned desiderata $(a),(b),(c)$, and $(d)$. Lewis's original model is designed to keep track of the kinematics of conversation or, in other words, to describe how the moves made in a language game affect its score. The score-keeping model of illocutionary games, by contrast, tracks conversational dynamics ${ }^{1}$; that is to say, it is concerned not only with the trajectories of contextual parameters such as presuppositions, permissibility facts, standards of precision, and rankings of comparative salience (Lewis 1979) — not to mention commitments, obligations, rights, and entitlements (Sbisà 1984, 2002, 2007, 2009)_but also with the forces responsible for bringing about changes in the conversational score. For this reason, I claim, it may shed light not only on the mechanisms underlying the functioning of presumptions, but also on the conditions under which utterances put forth as presumings succeed in

\footnotetext{
1 I would like to thank one of the reviewers for drawing my attention to the difference between conversational kinematics and conversational dynamics or, in other words, between the study of conversational movements and the study of conversational forces.
} 
bringing about warranted changes in the normative statuses of the participants in a dialogue as well as of the claims they make.

Before I get into the details, however, I would like to make a few general points about the goals of speech-act based models as well as the place they occupy among other theoretical accounts of presumptions.

There are two distinct approaches to studying presumptions: cognitive and conversational. According to the first one, presumptions should be viewed and accounted for as belief-like mental states or, more specifically, as propositional attitudes akin to what Stalnaker $(2002,2014)$ calls acceptance states. For Stalnaker,

[a]cceptance $(\ldots)$ is a category of propositional attitudes and methodological stances toward a proposition, a category that includes belief, but also some attitudes (presumption, assumption, acceptance for the purposes of an argument or an inquiry) that contrast with belief, and with each other. To accept a proposition is to treat it as true for some reason. One ignores, at least temporarily, and perhaps in a limited context, the possibility that it is false (Stalnaker 2002, p. 716).

According to Lewiński (2017, p. 597), one variant of the cognitive approach comes from John R. Searle, who claims that presumptions are intentional states that, when expressed with words, give rise to presumptions construed as speech acts; in general, an utterance that takes effect as a felicitous presumption expresses a corresponding mental presumption and the force and the meaning of the act thereby performed is determined by or at least corresponds to the mode and the content of the expressed mental state. On the cognitive approach, then, presumptions are primarily mental phenomena and are to be viewed as discourse-independent thoughts: pre-existing intentional states that wait for an appropriate conversational occasion to be expressed with words (for a discussion of the notion of discourse-independent thoughts, see Jaszczolt and Witek 2018).

According to the conversation-oriented approach, by contrast, presumptions are produced and function in conversational settings and as such can be described as conversational stances, procedures, claims, premises, conclusions, or speech acts. Derivatively, we can also speak of presumptions construed as mental states that are formed and expressed in the course of progressing discourse. More specifically, mental presumptions exist in virtue of being expressed in corresponding acts of presuming and exhibit what Slobin (1996) calls 'thinking for speaking.' In other words, they form a subclass of discourse-constituted thoughts: intentional states that one would not have if one did not express them ${ }^{2}$ (Jaszczolt and Witek 2018).

In what follows, I adopt the conversation-oriented perspective. ${ }^{3}$ More specifically, I assume that at least some of the phenomena described as presumptions can be

\footnotetext{
2 The idea of "a belief that one would not have if one did not express it" (Stalnaker 2002: p. 711) plays a key role in Stalnaker's account of informative presuppositions and his model of sequential update; for a discussion of this model see Witek (2019a, pp. 176-180).

${ }^{3}$ It is instructive to stress that by adopting the conversational perspective we shift our focus from the traditional question "What are the grounds and principles that warrant presumptive inferences?" (see Lewiński 2017) to a new one: "What is it for a given utterance to be a felicitous illocutionary act of making a presumption?" or, in other words, "What are the felicity conditions_-preparatory and essential—for the successful performance of presumptive speech acts?".
} 
adequately accounted for within the framework of the score-keeping model of illocutionary games. It is worth stressing, however, that the speech-act approach is not the only option for those who adopt the conversation-oriented perspective on presumptions. For instance, Godden (2017) offers a content-based theory, the central tenet of which is that presumptions should be understood as communicated contents, rather than as speech acts, that is to say, "as claims, rather than as kinds of claimings." (Godden 2017: p. 488) According to him, presumptions are propositions expressed by sentences of the form 'Presumably, $p$,' where the modal indicator 'presumably' indicates the presumptive status attached to the proposition that $p$. Godden's aim, then, is to specify the satisfaction conditions for sentences of the form 'Presumably, $p$ ' and thereby to arrive at a theory that meets the above-mentioned requirements, with a special emphasis on $(b)$ and $(d)$. The central goal of speech-act based theories, by contrast, is to specify the conditions under which one can perform a felicitous act of presuming and, next, use the resulting model to account for the dynamics of the burden of proof as well as for the dynamics of presumptive statuses conferred on propositions put forth in a dialogue; in short, they focus on requirements $(a)$ and $(c)$, respectively. It seems to me, however, that the observed difference in focus does not necessarily lead to a strict division of labour between the two approaches. My general aim in this paper, then, is to show that the score-keeping model of illocutionary games enables us not only to account for the dynamics of discursive obligations and presumptive statuses, but also to describe conditions under which presumptions take effect as warranted conversational moves.

To this end, I put forth and defend two hypotheses. According to the first one, presumptions construed as speech acts can be grouped into three illocutionary act types defined by reference to how they affect the state of a conversation; more specifically, I distinguish between (i) the unilateral act of individual presumption, the point of which is to shift the burden of proof by making the hearer committed to justifying his refusal to endorse the proposition communicated by the speaker, whenever he refuses to endorse it, (ii) the bilateral act of joint presumption- 'bilateral' in that it is performed jointly by at least two conversing agents- the function of which is to confer on the proposition endorsed by the speaker the normative status of jointly "recognised yet tentative acceptability" (Lewiński 2017, p. 592), and (iii) the indirect or back-door act of collective presumption, the purpose of which is to sustain rules and practices to which the conversing agents outsource (Langton 2015) or defer (Corredor 2017) the felicity of their conversational moves. In particular, I argue that the notion of individual presumption enables us to elaborate on the idea of presumptions as means for reallocating the burden of proof, and thereby to satisfy desiderata $(a)$ and $(b)$, whereas the category of joint presumption is well-suited for explaining the practical function of presumption and, by the same token, developing a theory that meets requirements $(c)$ and $(d)$; the notion of collective presumption, in turn, enables us to shed light on what Lewiński calls 'framework presumptions:' principles defining “the conditions of the possibility for meaningful linguistic communication.” (Lewiński 2017, p. 599) According to the second hypothesis, the functioning of individual, joint, and collective presumptions involves two types of mechanisms: the direct mechanism of illocution and the indirect one of accommodation. 
The account offered in this paper is to some extent stipulative. It is instructive to stress, namely, that the proposed justification of the first hypothesis does not require arguing that in English 'presume' is an illocutionary verb and 'I presume that' is a performative prefix the function of which is to indicate or make explicit the force of making a presumption. In other words, rather than examining the meaning and etymology of the English verb 'presume,' I use the score-keeping model of illocutionary games to define three notions-individual presumption, joint presumption, and collective presumption - and argue that they are useful conceptual tools to explain certain discursive phenomena that exhibit pre-theoretical characteristics of presumptions. In this regard, I follow the method used by Langton (2015, 2018), who uses the scorekeeping model of language games to argue that there are illocutionary act types for which there may be no corresponding performative formulas; what matters is that they are definable by reference to how their performance affects the state or score of a conversation. Unlike Langton, however, I claim that the production of essential effects of directly or explicitly made illocutionary acts-e.g., the speaker's obligation brought about by her promise, the hearer's obligation created by the speaker's order, and so on-has nothing to do with accommodation and should be accounted for along the lines suggested by the second hypothesis: i.e., in terms of illocution construed as a direct mechanism governed by rules of illocutionary dynamics.

Another reason for which the proposed account is to be regarded as stipulative is that it takes presumptions to be relatively rare phenomena that occur only in some types of language games. In other words, the proposed model pertains directly to language games that require thoughtful, attentive and critical players who normally are aware of the fact that their current epistemic situation entitles them to presume something rather than to assert it (I use the term 'normally' to leave room for unintended presumptions or, more generally, for acts the actual force of which is determined by external conditions and the hearer's uptake rather than by what the speaker has in mind). One example of such a game, which I discuss in Sect. 3.1, is the Popperian game of testing and falsifying scientific hypotheses that involves the cooperation of critical researchers who jointly accept the so-called basic statements (Popper 2005) and use them as potential falsifiers unless and until there are no compelling reasons to do otherwise. In my view, the Popperian game is governed by a norm according to which in certain circumstance the players should make presumptions rather than assertions; what is more, it is constituted by procedural and methodological standards that provide an adequate context in which individual and joint presumptions can take effect as felicitous conversational moves bringing about warranted shifts of the burden of proof and warranted presumptive statuses, respectively. My contention, however, is that at least in some cases the standards in question can be transferred and applied to less formal types of discourse. To say that the proposed model pertains directly to certain formalized and institutionalized language games, then, is not to claim that it cannot be applied outside these restricted conversational contexts. In my view, it can be used to account for some everyday argumentative dialogues, provided their participants jointly recognize that they are not able to settle their dispute without tentatively accepting some propositions as reasonable though defeasible premises.

The paper is organized as follows. In Sect. 2, I present the score-keeping model of illocutionary games; I begin with a brief discussion of its basic tenets and dis- 
tinctions (Sect. 2.1), move to a critical evaluation of its original Lewisian (1979, cf. Langton 2015) version, which I call panaccommodationalism about illocutionary acts (Sect. 2.2), and end up by elaborating on the ideas of back-door speech acts (Langton 2018), uptake (Austin 1975; Sbisà 2009), and blocking (Langton 2018; cf. Sbisà 1999) (Sect. 2.3). In Sect. 3, I use the score-keeping model to account for the functioning of presumptions understood as speech acts; in particular, I define and discuss three notions-individual presumption (Sect. 3.1), joint presumption (Sect. 3.2), and collective presumption (Sect. 3.3) -focusing on the dynamic and normative aspects of the phenomena they refer to. In Sect. 4, I use the proposed account to discuss some issues raised by three speech-act based models to be found in the literature: Walton's (1993) theory of presumptions as speech acts standing half way between assertions and assumptions, Bermejo-Luque's (2016) account of presumptions as constituting a subtype of constatives in Bach and Harnish's (1979) sense, and Cristina Corredor's (2017) model of presumptions as Austinian verdicitives.

\section{Score-keeping in illocutionary games}

\subsection{Illocution and accommodation}

A key idea behind the score-keeping model of illocutionary games (Witek 2015c) is that speech acts in general and illocutionary acts in particular can be categorized by reference to how they affect the context or state of conversation. In short, speech acts are "context-changing social actions" (Sbisà 2002, p. 421) that can be represented as functions "from contexts into contexts" (Gazdar 1981, p. 68). Following Lewis (1979), the context or state of conversation is represented as the conversational score (Langton 2015, 2018) or conversational record (Thomason 1990; Lepore and Stone 2015; cf. Witek 2016), understood as a sequence of abstract objects representing contextual features that $(a)$ have a bearing on the appropriateness of and $(b)$ can be affected by the moves made in a language game. In other words, the score of a language game performs two functions: first, it (a) defines, for every stage of the game, the scope of speech acts that can be appropriately made at that state; second, it $(b)$ tracks and represents effects that the acts have on the context of their production.

Taking into account its kinematic or, more accurately, dynamic function $(b)$, then, the score can be defined as an abstract data structure that tracks and represents publicly recognizable effects that speech acts have on the state of conversation. In other words, it registers every change to the state of conversation that would be recognized by a competent speaker; i.e., by anyone who knows and abides by shared linguistic and conversational standards: syntactic and semantic rules, discursive norms, conventional procedures, and so on. Focusing on its interpretative or evaluative function $(a)$, in turn, the score at a given stage of a game can be described as a sequence of abstract entities relative to which every move made at that stage is to be interpreted and evaluated. Depending on the particular type of game under scrutiny, its score can include such components as the system of presuppositions shared by interlocutors (Stalnaker 2002, 2014), the nexus of second-personal normative relations (Heal 2013) or deontic facts (Sbisà 2002, 2009, 2019), understood as obligations, commitments, rights, and 
entitlements of the conversing agents, the set of points of reference for interpreting anaphoric expressions, rankings of comparative salience, standards of precision, and so on. In short, for every contextual factor that has a bearing on the appropriateness of the moves made in a game, there is a corresponding score component that tracks its kinematics or dynamics.

Speech act types construed as types of conversational moves, then, can be represented as functions from scores to scores. Consequently, every speech act token can be represented as an ordered pair, the first element of which is its source score (the score representing the stage at which the act is performed and relative to which it has to be evaluated and interpreted) and the second element of the pair is its target score (the score that represents the state of conversation as affected by the performance of the act). By way of illustration, let us consider a situation in which Jones utters to Smith the following sentence:

(1) You are now permitted to cross the white line. ${ }^{4}$

Let us assume that Jones is a master, and Smith is a slave: The former controls the latter by determining the boundary between what Smith is permitted to do and what he is not permitted to do. More specifically, Jones controls Smith by performing exercitive acts that enact new norms and bring about new permissibility facts. Generally speaking, exercitive acts are "the exercising of powers, rights, or influence" (Austin 1975, p. 151) and their point is to give "a decision in favour of or against a certain course of action, or advocacy of it” (Ibid., p. 156). In particular, in uttering sentence (1), Jones exercises his power as a master in order to enact a new norm for Smith by shifting the boundary between what is permissible and what is impermissible. The felicity of the exercitive act under discussion presupposes Jones's authority as master; in other words, his authority is an Austinian presupposition of the act (Austin 1975, p. 48n; cf. Corredor 2017; Witek 2013a, 2015c) and as such contributes to the source score-let us refer to it as ' $\operatorname{Sc}_{S}(1)$ ' - relative to which Jones's conversational move is to be interpreted and evaluated. The exercitive takes effect by enacting a new norm for Smith or, in other words, by shifting the boundary between what he is and what he is not permitted to do; the new permissibility fact thereby created contributes to the target score-let us refer to it as ' $\mathrm{Sc}_{\mathrm{T}}(1)$ ' - that represents the state of conversation as affected by Jones's utterance. In short, the illocutionary act that Jones makes in uttering (1) can be represented as an ordered pair $\left\langle\operatorname{Sc}_{\mathrm{S}}(1), \operatorname{Sc}_{\mathrm{T}}(1)\right\rangle$.

It is instructive to note that components of $\mathrm{Sc}_{\mathrm{S}}(1)$ and $\mathrm{Sc}_{\mathrm{T}}(1)$ are principally determined by rules specifying correct play and rules specifying the kinematics of score, respectively (Lewis 1979, p. 345). Let us call the former rules of appropriateness, and the latter rules of kinematics or, more accurately, rules of illocutionary dynamics. Rules of appropriateness are akin to what Searle (1969) tabbed as preparatory rules or, more generally, to the felicity rules that constitute Austinian conventional procedures for the performance of speech acts (Austin 1975, pp. 14-15); roughly speaking, they define the conditions under which the act can be felicitously made or, to put it in different terms, its Austinian presuppositions (for a discussion of this issue, see Witek 2013a, 2015c). Rules of illocutionary dynamics, in turn, may be described by

\footnotetext{
${ }^{4}$ I borrow this example from Langton (2018), who uses it to discuss the Lewisian master-slave game (Lewis 1979: pp. 340-341).
} 
reference to Searle's (1969) notions of essential effects and essential rules of the form ' $X$ counts as $Y$ in context $C$ ' ${ }^{5}$. They determine, for every type of conversational move that can be made in a game, how the move affects the score of the game. For instance, according to one of the dynamics rules of the master-slave game, the utterance of sentence (1) counts as the production of a new permissibility fact-that the slave is permitted to cross the white line-provided the speaker has the required authority as a master; the new permissibility fact thereby created is the Searlean (1969) essential effect of Jones's exercitive act.

Example (1) illustrates how the mechanism of illocution works. Roughly speaking, it is a direct mechanism responsible for the production of normative effects of moves made in a language game. It is direct, because it makes use of illocutionary dynamics rules of the form ' $X$ counts as $Y$ in context $C$ :' making move $X$ in context $C$ represented as source score $\operatorname{Sc}_{\mathrm{S}}(X)$ counts as contributing normative state $Y$ to target $\operatorname{score~} \mathrm{Sc}_{\mathrm{T}}(X)$. In the case under discussion, uttering (1) in the context represented by $\mathrm{Sc}_{\mathrm{S}}(1)$ - the source score, one component of which is Jones's authority as master-counts as the production of a new norm or permissibility fact for Smith. This is how exercitives qua illocutions work.

By analogy, let us consider a situation in which Jones utters to Smith the following words:

\section{(2) Go and pick up wood. ${ }^{6}$}

In uttering (2), Jones performs a directive act: He orders Smith to go and pick up wood. The felicity of this utterance qua an order presupposes Jones's authority as a master and consists in putting Smith under an obligation to go and pick up wood. The obligation thereby created is a normative or essential effect of Jones's act and as such contributes to target score $\mathrm{Sc}_{\mathrm{T}}(2) .{ }^{7}$ The authority in question, in turn, is an Austinian presupposition of the act and as such plays a key role in source score $\mathrm{Sc}_{\mathrm{S}}(2)$. In short, the utterance of (2) in a context that satisfies this presupposition puts Jones under a new obligation and turns source score $\mathrm{Sc}_{\mathrm{S}}(2)$ into target score $\operatorname{Sc}_{\mathrm{T}}(2)$. This is how directives qua illocutions work.

In general, exercitives, directives, and other illocutionary acts take effect (Austin 1975 , p. 117) by bringing about characteristic changes in the normative domain of "rights, obligations, entitlements, [and] commitments of the participants" (Sbisà 2002, p. 434) in discourse; in other words, their proper function is to modify the "nexus of second-personal normative relations" (Heal 2013, p. 140) between the communicating agents. Normally, the mechanism whereby they perform this function involves illocution only; that is to say, in most cases, the normative change brought about by a felicitous speech act comes down to the production of its essential effect. As Jane

\footnotetext{
5 In fact, every speech act rule of the form ' $X$ counts as $Y$ in context $C$ ' can be analysed into two components: one concerning kinematics or dynamics (the production of $X$ in context $C$ brings about $Y$ ), and the other concerning appropriateness (it is appropriate to use $X$ to produce $Y$ only if contextual requirement $C$ is satisfied).

6 I borrow this example from Austin (1975: p. 28); recently it has been discussed by Langton (2015) and Witek (2013a, 2015c).

7 It is instructive to stress that in calling this obligation the essential effect of Jones's act I depart from Searle's (1969) original model, according to which the essential effect $Y$ of a directive act is an attempt to get the hearer to do something. I am grateful to one of the reviewers for drawing my attention to this point.
} 
Heal notes, the effect in question - the change "in normative relations [that is] integral to what is brought about with [a] successful [act]" (Heal 2013, p. 141) -may be quite complex. For instance, the essential effect of an order made in uttering (2) involves, besides Smith's obligation to go and pick up wood, Jones's entitlement to expect Smith to go and pick up wood, as well as Jones's right to reproach or even punish Smith if he fails to comply with what he is told. Independently of its complexity, however, it may be represented as ' $Y$ ' in the relevant ' $X$ counts as $Y$ in context $C$ ' formula.

In some cases, however, a speaker who makes a felicitous order in uttering (2) not only produces the essential effect of her act, but also implicitly establishes her authority over her audience, thereby satisfying one of the Austinian presuppositions of her act. In other words, the total change her act brings about in the domain of normative facts may go beyond what is represented as ' $Y$ ' in the relevant ' $X$ counts as $Y$ in context $C$ ' formula. In short, the functioning of a felicitous order may involve not only illocution, but also accommodation.

The term 'accommodation' was introduced by Lewis (1979). Roughly speaking, it stands for a context-repairing or context-adjusting process that is guided by the default assumption that the speaker's utterance counts as "correct play" (Lewis 1979, p. 347) or, in other words, that it constitutes an appropriate conversational move of a certain type. ${ }^{8}$ According to Lewis, it is governed by rules of accommodation that constitute a subtype of kinematics rules. Following Sbisà (2019; cf. Witek 2019a), however, I assume that accommodating processes involve no rules of their own. In my view, we should rather speak of mechanisms of accommodation that function against the background of appropriateness rules and modify source scores rather than target scores; in particular, accommodating mechanisms may make the Austinian presupposition of an act fulfilled and, as a result, maintain the default presumption that the act constitutes correct play. As Lewis puts it, the felicitous performance of an act "requires and thereby creates" (Lewis 1979, p. 339; cf. Langton 2015) what is required. Even though I have some reservations about this formula-which I explain in Sect. 2.2-let us use it to discuss the following example.

Let us suppose that Jones, Smith and other passengers of a sea cruise have survived a heavy storm and find themselves on a desert island. They are shocked. Nobody knows what to do. Jones decides to take charge and utters (2) to Smith. Smith complies with what he is told. In other words, Smith takes Jones's utterance to be a binding order. In doing so, he accommodates what the felicity of the order presupposes, namely Jones's authority as the leader of the shipwrecked group. Jones's utterance takes effect as a binding order; its felicitous performance requires and thereby creates Jones's authority over Smith and possibly other survivors. ${ }^{9}$ Roughly, this is how the mechanism of accommodation works.

\footnotetext{
8 There is no commonly agreed definition of accommodation. As Mandy Simons observes, it involves "some redressive action on the part of the addressee" (Simons 2003: p. 258) that can be described either in terms of context-fixing (Lewis 1979) or context-adjustment (Stalnaker 2002, 2014). According to Thomason (1990), in turn, accommodation is best understood as a cooperative act that consists in removing obstacles to the achievement of one's interlocutor's recognised goals. For a survey of received models and accounts of accommodation, see Roberts (2015) and Witek (2019a).

9 A similar example is discussed by Thomason (1990: p. 342), who considers an indirect mechanism whereby one can become the informal leader of a group.
} 
Of course, the above-presented description of accommodation is oversimplified. Normally, the accommodation of authority relations is a complex process embracing a series of interactional events, each of which involves the speaker performing a certain speech act and the audience going along with it. Accommodation takes time. What is more, its success requires that some other conditions are met. It requires, first, that nobody defuses the speaker's acts by saying that she is not entitled to perform them (more on this in Sect. 2.3); second, that the speaker was not endowed with the power to issue the acts under discussion before; and, third, that she and her audience are familiar with the practice of performing them. On the desert island, nobody objects by saying to Jones, "Who do you think you are?" or "I do not take orders from you." Before the crash, the survivors did not know each other; in particular, there were no pre-established authority relationships between them. As competent social agents, however, they are all familiar with the institution or game of issuing and obeying orders.

In sum, there are two types of mechanisms-illocution and accommodation-that are responsible for producing normative facts with words or, to put it in different terms, for modifying the nexus of normative relations among participants in social life. Illocution is a direct mechanism guided by dynamics rules: To produce a new normative fact $Y$ by making an utterance $X$ is to follow an essential rule of the form ' $X$ counts as $Y$ in context $C$.' Accommodation, in turn, has no rules of its own, but functions against the background of appropriateness rules that determine, for every speech act type that can be made in a given game, the conditions of its felicitous performance or, in other words, its Austinian presuppositions; that is to say, it is guided not by rules of accommodation, but by a general expectation that the speaker's utterance constitutes correct play according to the standards defined by appropriateness rules. In short, the appropriate or felicitous performance of a speech act requires and thereby creates what it requires:

If at time $t$ speaker $S$ makes binding illocutionary act $I$, and if the felicity of $I$ requires Austinian presupposition $p$ to be part of the score relative to which $I$ is evaluated, and if $p$ is not part of the score just before time $t$ at which $I$ is made, then — ceteris paribus and within certain limits $-p$ becomes part of the score at $t$ (Witek 2015c, p. 18).

\subsection{Panaccommodationalism about illocutionary dynamics}

According to the view I call panaccommodationalism, essential effects of illocutionary acts-norms and permissibility facts enacted by exercitives, obligations created by directives, naming-relations brought about by baptisms, and so on-are produced by following respective rules of accommodation, the general pattern of which goes as follows:

(L) "If at time $t$ something is said that requires component $s_{n}$ of conversational score to have a value in the range $r$ if what is said is to be true, or otherwise acceptable; and if $s_{n}$ does not have a value in the range $r$ just before $t$; and 
if such-and-such further conditions hold; then at $t$ the score-component $s_{n}$ takes some value in the range $r$ " (Lewis 1979, p. 347).

The proponents of the view in question seem to claim that every change in the nexus of normative relations is produced by following the Lewisian pattern (L).

There are two versions of panaccommodationalism: one proposed by David Lewis (1979) and the other by Rae Langton (2015). In "Scorekeeping in a language game," Lewis argues that the mechanism whereby permissibility facts are produced involves accommodation; for instance, Jones's utterance of (1) enacts a new norm for Smith ${ }^{10}$ by following the rule of accommodation for permissibility:

If at time $t$ something is said about permissibility by the master to the slave that requires for its truth the permissibility or impermissibility of certain courses of action, and if just before $t$ the boundary is such as to make the master's statement false, then-ceteris paribus and within certain limits-the boundary shifts at $t$ so as to make the master's statement true (Lewis 1979, p. 341).

Provided Smith has the required authority as master, his utterance of (1) is to be interpreted in light of the general presumption according to which whatever the master says about the permissibility of some course of action is true. In other words, the presumption of truthfulness - as well as the expectation it gives rise to-guides the accommodating mechanism that produces the essential effect of Jones's exercitive act.

In a similar vein, Lewis contends that illocutionary acts performed with the help of explicit performative formulas take effect by following rules of accommodation. What is more, he claims that the accommodating mechanism underlying the functioning of explicit performative talk is guided by the expectation of truthfulness, too. To illustrate his point, he considers a situation in which a speaker, who is entitled to perform the ceremony of naming a ship, utters the following words:

(4) I name this ship the Queen Elizabeth. ${ }^{11}$

Performative sentences are well-formed syntactic objects with truth conditions (cf. Lewis 1970, p. 59n). Pace Austin, then, Lewis argues that in uttering (4) the speaker triggers an accommodating process that is guided by the expectation of truthfulness. More specifically, the process follows the rule of accommodation for explicit acts of naming:

If at time $t$ something is said that requires for its truth that ship $s$ bear name $n$; and if $s$ does not bear $n$ just before $t$; and if the form and circumstances of what is said satisfy certain conditions of felicity; then $s$ begins at $t$ to bear $n$ (Lewis 1979, p. 356).

\footnotetext{
10 In fact, Lewis considers an abstract example involving a master, a slave, and acts of saying or statements "that such-and-such courses of action are impermissible" (Lewis 1979: p. 340). For the sake of simplicity, however, I continue calling the master and the slave 'Jones' and 'Smith,' respectively, and focus on sentence (1) as a linguistic tool for establishing new permissibility facts.

11 This example comes from Austin (1975: p. 5). Austin also discusses a situation in which a speaker who is not the person chosen to name the ship utters the sentence 'I name this ship the Mr. Stalin' (Ibid: p. 23), thereby producing an instance of a misfire. In his discussion of explicit performatives, in turn, Lewis (1979: p. 355) considers the sentence 'I hereby name this ship the Generalissimo Stalin.'
} 
According to Lewis, one of the conditions under which the utterance of (4) is true is that the ship bears the name 'Queen Elizabeth' (other conditions specify that it did not bear the name beforehand, the speaker makes it the case that the ship begins to bear the name, and she does it by uttering sentence (4), and so on). In short, the truth of (4) requires that the ship bears the name 'Queen Elizabeth.' The recognition of this requirement triggers the accommodating process in virtue of which the ship begins to bear this name. According to Lewis, then, essential effects of acts of naming are produced through accommodation.

It is instructive to note that in his account, Lewis assumes that the primary function of exercitive acts and that of explicit performative utterances is to say something true: if they fail to perform this function, they cannot be regarded as constituting correct play. In particular, for an utterance of (1) to be an appropriate act in the master-slave game is for it to be a true "statement about permissibility" (Lewis 1979, p. 341); likewise, the utterance of (4) is an appropriate conversational move only if it is true. It can be said, then, that Lewis's approach is in a sense reductionist: He seems to assume, first, that most conversational moves we make are statements - speech acts the point of which is to produce true linguist representations of worldly states-and, next, attempts to account for their other illocutionary forces in terms of accommodation. ${ }^{12}$ In my view, it is this kind of reductionism-developed in detail in "General semantics" (Lewis 1970) — that motivates Lewis's version of panaccommodationalism.

The version of panaccommodationalism developed by Langton (2015), by contrast, is free from the reductionism inherent in Lewis's theory. As a result, her model applies directly and unequivocally to indicative and imperative utterances, too. Examining the desert island scenario, for instance, Langton argues that in uttering sentence (2), Jones triggers two mechanisms that function in parallel: the mechanism of illocutionary accommodation, which brings about Smith's obligation to pick up wood, and that of presupposition accommodation, which produces Jones's authority as the leader of the shipwrecked group; if Jones's order was issued with a pre-established authority, its functioning would involve illocutionary accommodation only.

According to Langton, then, both the essential effect of Jones's order and his authority as the shipwrecked group leader are produced by following the Lewisian pattern (L). She argues that Jones's utterance qua a binding directive requires for its success, first, that Smith is under an obligation to go and pick wood and, second, that Jones stands in an appropriate authority relation to Smith. The former requirement plays a key role in the mechanism of illocutionary accommodation, whereas the latter guides the mechanism of presupposition accommodation. In both cases, "[w]hat is said 'requires and thereby creates' what is required, following a rule of accommodation" (Langton 2015, p. 2).

Let us consider a more detailed application of Langton's two-part model to the desert island scenario.

Part I. Presupposition Accommodation of Authority

If (1. Utterance) — at time t something is said [Jones says to Smith, 'Go and pick up wood!']; and

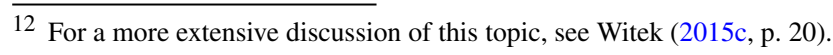


(2. Requirement) - a score component is required to be a certain way [Jones has authority] in order for what is said to be correct play [a felicitous order]; and (3. Novelty) - the component wasn't that way before; and

(4. Conditions) — certain conditions hold [e.g. Smith falls in, treats Jones as having authority]; then

(5. Creation) - at $\mathrm{t}$ the score component is that certain way [Jones has authority], enabling what is said to be correct play [a felicitous order] (Langton 2015, p. 16).

Part II. Illocutionary Accommodation of [Obligation]

If (1. Utterance) — at time t something is said [Jones says to Smith, 'Go and pick up wood!']; and

(2. Requirement) - a score component is required to be a certain way [Smith is obliged to go and pick up wood] in order for what is said to be correct play [a felicitous order]; and

(3. Novelty) - the component wasn't that way before; and

(4. Conditions)—certain conditions hold [e.g. Jones has authority].

(5. Creation) - at t the score component is that certain way [Smith is obliged to go and pick up wood], enabling what is said to be correct play [a felicitous order] (Langton 2015, p. 17).

Both Part I and Part II exhibit the Lewisian pattern (L) and elaborate on the 'requires, and thereby creates what is required' formula. It is instructive to note, however, that the verb 'require' that is used in Langton's description of Part I and Part II is ambiguous. To say that Jones's utterance qua an order requires for its success that he has authority over Smith is just to say that it presupposes that Jones stands in an appropriate authority relation to Smith; by contrast, to say that the utterance qua an order requires for its success that Smith is obliged to pick up wood, is to say that it results in or constitutes putting Smith under an obligation to go and pick up wood. In short, in the description of Part I, the verb 'require' should be paraphrased as 'presuppose,' whereas in the description of Part II, it should be read as 'constitute.'

In my view, this distinction between the two senses of 'require'-between its presuppositional sense and its constitutive sense, respectively-sheds light on a fundamental difference between what Langton calls presupposition accommodation and illocutionary accommodation or, to put it in different terms, between accommodation and illocution. In a nutshell, presuppositional requirements are placed on prior contexts, whereas constitutive requirements are imposed on posterior contexts. More specifically, what Langton calls presupposition accommodation is a retroactive mechanism that repairs or adjusts the source score of an act and as such functions against the background of appropriateness rules; what she calls illocutionary accommodation, in turn, is a prospective mechanism that updates the source score or, more accurately, turns it into the target score in accordance with the relevant dynamics rule. In sum, the difference between the two mechanisms in question corresponds to the contrast between presupposing a normative fact and constituting it; it also corresponds to the distinction between contextual requirements that should be met prior to the act, and requirements that are put on the context that is being altered by the act. Because of these and related differences, then, it is better to speak of illocution and accommoda- 
tion as two distinct types of mechanisms, rather than as two types of accommodation: illocutionary and presupposition.

One might say that the dispute is purely verbal and that the only difference between the view advocated in this section and the one developed by Langton lies in terminology. One might also add that what matters is that the two mechanisms under scrutiny-the retroactive context-repairing mechanism and the prospective contextmodifying one-exhibit a common pattern that can be described with the help of the Lewisian formula (L). In my view, however, the dispute is not verbal, but methodological. It concerns reasons and motives behind introducing new categories and drawing novel conceptual distinctions. Langton's two-part model is intended to "shed light on the diverse and unnoticed ways a speech act can create a norm; highlight the unity in this diversity, in their conformity to a rule of accommodation; and bring out their dependence (obvious and subtle) on the dynamics of authority, as a condition of their success" (Langton 2015, p. 7). My contention, however, is that the diverse mechanisms of getting norms from speech acts, even though they can be described with the help of the Lewisian pattern (L), fail to form a natural class. Therefore, using the term 'accommodation' to describe all of them can be misleading. More crucially, by attempting to account for the production of essential effects of speech acts along the lines of the Lewisian pattern (L), we run the risk of arriving at a distorted picture of illocutionary dynamics. I do agree that the normative presupposition of an act - the speaker's authority or deontic power to perform it—can be produced by a context-repairing mechanism whose structure is adequately captured by pattern (L). In my view, however, the act's essential effect - the change it brings about, in virtue of being of a certain type, in the domain of normative relations among the conversing agents-is produced be a mechanism that involves no context-repairing and, in this connection, cannot be adequately described along the lines of formula (L).

Let me conclude this subsection by emphasizing one difference between the two versions of panaccommodationalism discussed above. Lewis distinguishes rules of accommodation from other rules of kinematics (dynamics) or, in other words, from rules of direct kinematics (dynamics): the latter are responsible for the production of essential effects of conversational moves and as such can be represented as functions from source scores to target scores; the rules of accommodation, in turn, govern context-repairing processes and as such can be represented as functions from defective source scores to repaired source scores. According to Langton, in turn, both essential effects and Austinian presuppositions of speech acts follow rules of accommodation. In this respect, it seems, Langton goes further than Lewis. Lewis's panaccommodationalism about illocutionary dynamics seems to be a downstream effect of his reductionist approach; i.e., his attempt to reduce moves made in illocutionary games to acts whose proper purpose is to produce true linguistic representations of worldly states. Langton's version of the view in question, in turn, is motivated by the need to stress the alleged unity in the variety of norm-producing discursive processes. As a result, she seems to blur the line between rules of direct dynamics and rules of accommodation, between direct mechanisms of modifying context and indirect ones of repairing or adjusting it.

Following Lewis and pace Langton, I limit the use of the term 'accommodation' to context-repairing or context-adjusting processes and distinguish them from pro- 
cesses of direct dynamics. Unlike Lewis, however, I claim that there are no rules of accommodation that constitute a subtype of dynamics rules. Following Sbisà (2019, pp. 39-44), I take accommodation to be a discursive mechanism that has no rules of its own, but functions against the background of appropriateness rules; in short, even though it is not ruled-governed, it is rule-dependent.

\subsection{Back-door speech acts, uptake, blocking, and defusing}

Context-repairing or context-adjusting processes of accommodation underlie the functioning of what Langton (2018) calls back-door speech acts, one example of which are conversational exercitives in McGowan's (2004, 2009) sense; i.e., implicit acts of norm-enacting. Among the speech acts that make use of similar mechanisms are back-door verdictives: e.g., implicit rankings and implicit testimonies (Langton 2018). Generally speaking, back-door speech acts work covertly by exploiting mechanisms akin to the ones underlying informative presuppositions (Stalnaker 2002, 2014; von Fintel 2008). More specifically, they produce new score components-norms, rankings, testimonies, and so on-by presenting them "as uncontroversial and not at issue - as shared knowledge or received wisdom, to be taken for granted, what we all know already, and know that we know already" (Langton 2015, p. 27). By way of illustration, let us consider the following situation described by Langton (2018). At a Melbourne football game, a St. Kilda supporter shouts to a sluggish player:

(5) Get on with it, Laurie, you great girl!

According to Langton, in uttering (5) the supporter triggers a series of back-door speech acts: an implicit ranking ("women are inferior"), testimony ("there is something wrong with girls"), and exercitive or norm-enactment ("it is permissible to treat women as inferior"). Another example of a back-door testimony is a message indirectly conveyed by a daughter who utters the following words to her father (von Fintel 2008, p. 163):

(6) Oh Dad, I forgot to tell you that my fiancé and I are moving to Seattle next week.

In uttering (6), the daughter performs a back-door speech act, the point of which is to inform her father that she is engaged. Moreover, there are also cases of back-door authority claims; for instance, in uttering (2) on the desert island, Jones implicitly claims his authority over other survivors.

Back-door speech acts can be accounted for along the lines of the score-keeping model of illocutionary games. What's more, the model can also shed light on blocking, understood as a response to implicit illocutions; on defusing, construed as an attempt to make explicitly performed acts "null and void" (Austin 1975, p. 31; for a discussion of annulling, see Caponetto 2018); and on the role of uptake in the functioning of accommodation. Let us, then, consider the phenomena of back-door speech acts, blocking, defusing, and uptake, thereby demonstrating the explanatory power of the model and setting the stage for its application to the examination of the functioning of presumptions.

To start with, let us take a closer look at the complex speech act performed by the aggressive St. Kilda supporter. In uttering sentence (5), he performs a directive act to get Laurie to play better and, at the same time, expresses his negative emotions 
and attitude towards Laurie's performance in the match. In making this directive-cumexpressive act, the supporter addresses Laurie with the phrase "you great girl" that, in this particular context, triggers a number of back-door speech acts that exploit the mechanism of presupposition accommodation: The supporter implicitly ranks women as inferior, testifies that there is something wrong with girls, and enacts or sustains a norm according to which it is permissible to treat women as inferior. Let us take, following Langton, that an alert bystander reacts by uttering the following words:

(7) Hey, what's wrong with a girl?

According to Langton, the point of the act made in uttering (7) is to get the supporter to say explicitly what he has communicated in the background by exploiting the backdoor method. In other words, the bystander makes an attempt to block the supporter's implicit illocutions by refusing to provide what can be called, following Austin (1975, p. 117; cf. Sbisà 2009), the hearer's uptake.

In general, illocutionary acts take effect-they succeed in modifying the system of interpersonal normative relations-provided they secure uptake on the part of the audience. In most cases, the securing of uptake amounts to "bringing about the understanding of the meaning and of the force of the locution" (Austin 1975, p. 117). One particularity of back-door speech acts is that they function covertly by exploiting the mechanism of accommodation and, in this connection, can succeed if they secure what Langton (2018) calls passive or default uptake; that is, if they go through unnoticed or, if recognized, are left without a response. In uttering (7), therefore, the bystander attempts to prevent the accommodation of what she takes to be faulty presuppositions of the supporter's act by forcing him to communicate them explicitly: When performed overtly, the act of ranking women as inferior-as well as the corresponding acts of testifying and norm-enacting — can be addressed and criticised.

By analogy, let us consider a situation in which Ann utters sentence (8):

(8) Even George could win.

In doing this, she explicitly asserts that George could win. At the same time, however, she performs the back-door speech act of testifying that George is an unpromising candidate. To block it, an alert bystander can ask question (9), thereby preventing an unnoticed adjustment of conversational score:

(9) Whadda ya mean, 'even George'? Is George an unpromising candidate?

It is instructive to note, however, that the act of blocking made in uttering (9) has no bearing on the felicity of Ann's explicit assertion to the effect that George could win. Let us consider, by contrast, an alternative version of the desert island scenario discussed in Sect. 2.1: Jones utters sentence (2), but Smith, rather than complying with what he is told, responds by saying:

(10) Who do you think you are, deciding what to do for us?

Let us note that in uttering (10), Smith not only blocks Jones's implicit authority claim, but also attempts to make Jones's purported order “null and void" (Austin 1975, p. 31; cf. Caponetto 2018). In other words, the point behind Smith's remark is to prevent the accommodation of the Austinian presupposition of Jones's purported order and thereby to defuse it by making it a misfire. 
In sum, blocking, understood as a response to back-door speech acts, is a form of counter speech (Langton 2018) in that it prevents presupposition accommodation. It can also result in defusing or making 'undone' explicitly made acts, if it prevents the accommodation of their Austinian presuppositions; i.e., of what is presupposed by their felicity. Viewed from the perspective of the score-keeping model presented in this section, then, blocking and defusing are conversational moves directed at what is accommodated and what is illocuted, respectively: even though blocking the Austinian presupposition of an act can automatically and straightaway result in defusing the act by making it 'null and void,' we can distinguish the former from the latter by abstraction. What is more, at least in some cases, we can speak of blocking without defusing; for instance, even though in uttering (9) the alert bystander blocks the accommodation of the pragmatic presupposition "George is an unpromising candidate" triggered by Ann's use of the adverb 'even,' this move has no bearing on the felicity of Ann's explicit assertion to the effect that George could win.

\section{Presumptions as speech acts}

As Walton notes (1993: p. 125), both Searle (1979) and Vanderveken (1990) make no room for presumptions in their taxonomies of speech acts. As far as I know, John L. Austin did not mention presumptions in his classification of illocutionary acts either (Austin 1975, pp. 148-164). In other words, 'presume' does not appear on his lists of illocutionary verbs grouped under the headings of verdictives, exercitives, commissives, behabitives, and expositives. One cannot find it in Marina Sbisà's (1984) refined version of the Austinian taxonomy either. Interestingly, the notion of presumption plays a key role in the Speech Act Schema developed by Bach and Harnish (1979); they claim, namely, that the inference whereby the hearer recognizes the speaker's communicative intention and, by the same token, the force and content of her act, exploits a number of conversational principles - the linguistic presumption, the communicative presumption, the presumption of literalness, Gricean maxims construed as conversational presumptions, and so on-which are operative unless there is contextual information to the contrary (Bach and Harnish 1979; see also Corredor 2017). However, they do not mention the speech act of presumption in their classifications of communicative and conventional illocutionary acts. In sum, classical taxonomies of illocutionary acts (Austin 1975; Bach and Harnish 1979; Searle 1979; Sbisà 1984; Vanderveken 1990) seem to make no room for the speech act of presuming.

In contrast, some argumentation theorists and philosophers working within the speech-act theoretic tradition take presumptions to form a type of illocutionary acts. Walton (1993) in "The Speech Act of Presumption" argues that presumptions are illocutionary acts standing half way between assertions and mere assumptions. What is more, following Searle's (1969) analysis of successful and non-defective promises, he sets out a number of speech-act conditions for presumptions and distinguishes between preparatory, placement, retraction, and burden conditions. Bermejo-Luque (2016), in turn, claims that acts of presuming — which, when performed correctly, reallocate the burden of proof among the participants in a critical discussion-form a subtype of constatives in Bach and Harnish's (1979) sense: communicative speech 
acts whose point is to "express the speaker's belief and [her] intention or desire that the hearer have or form a like belief." (Bach and Harnish 1979: p. 41; according to Bach and Harnish, for a speaker to express propositional attitude $A$ in making an utterance is to reflexively-intend the hearer to get the utterance as reason to think that the speaker has attitude A) Mitchell Green (2009; cf. Witek 2019c), in turn, argues that "[a]ssertions, conjectures, suggestions, guesses, presumptions and the like are cousins sharing the property of commitment to a propositional content. They differ from one another in the norms by which they are governed, and thereby in the nature of that commitment." (Green 2009, p. 157) According to him (Green 2009, p. 158), in presuming that $p$ the speaker shows her acceptance that $p$ as justified for current conversational purposes, where the term 'acceptance' is to be understood as standing for a belief-like propositional attitude in Stalnaker's (2002) sense ${ }^{13}$; in short, Green takes presumptions to belong to what he calls 'assertive family.' Cristina Corredor (2017), in turn, claims that presumptions constitute a subtype of verdictive speech acts in Austin's sense. The point behind making a presumption, she argues, is to present a certain claim or opinion as a reasonable endorsement (Corredor 2017: p. 581). In other words, to presume that $p$ is to put forth the proposition that $p$ as something reasonable enough to be endorsed and, at the same time, to presuppose in Austin's sense "that there must be some reasons available to the participants which justify [the proposition that $p$ ]." (Corredor 2017: p. 581) Interestingly, Corredor also considers whether presumptions can be regarded as exercitives in the sense of Austin (1975) and Sbisà (1984): speech acts whose point is to assign obligations, duties, or commitments to the addressee by exercising one's power or authority to do so. Nevertheless, she finally rejects this possibility and sticks to the idea that presumptions can be best understood as a subtype of verdictives.

In the remainder of this section, I argue that the two characteristic properties of presumptions discussed in Sect. 1-namely, that they act by $(i)$ redistributing the burden of proof among the participants in a critical discussion and (ii) conferring on certain propositions put forth in a dialogue the defeasible status of jointly recognized acceptability — can be adequately accounted for by assuming that to presume something is to perform a speech act the force of which is determined by the effect it has on the context of its production. However, rather than considering whether presumings should be rated as falling into one category or another-for instance, as forming a subtype of constatives, assertives, verdictives, expositives, or any other illocutionary type distinguished in the above-mentioned taxonomies of speech acts-I use the score-keeping model of illocutionary games to define two types of conversational moves that bring about effects $(i)$ and (ii), respectively. In this respect, the proposed account is to some extent stipulative. My contention, however, is that the constructed categories enable us to shed light on some of the presumptive phenomena investigated by argumentation theory. More specifically, in what follows I distinguish between (i) individual presumptions, the function of which is to reallocate the burden of proof among the participants in a conversation, and (ii) joint presumptions, the point of which is to confer on the contents communicated by speakers the defeasible status of jointly endorsed propositions that can be further used as premises in reasoning. I also define the notion

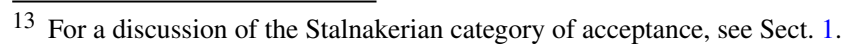


of (iii) collective presumptions that stands for back-door speech acts of sustaining collectively agreed upon procedures, rules and standards to which speakers outsource (Langton 2015) or defer (Corredor 2017) the authority or felicity of their explicitly made acts.

In my view, the Austinian approach to speech act theory (Austin 1975; Sbisà 1984, 2002, 2009, 2013, 2019; cf. Witek 2015a, b, c)—provides a natural framework for examining the functioning of presumptions in discourse. It defines illocutionary acts as "context-changing social actions" (Sbisà 2002, p. 421) that bring about "conventional and institutional states of affairs such as attributions of rights, obligations, entitlements, [and] commitments." (Ibid., p. 434) The normative effects of speech acts are conventional in that they exist in virtue of the intersubjective agreement between the relevant social partners and as such are "liable to defeasibility and cancellation." (Sbisà 2007, p. 470) In short, the force and type of an illocution depends on how its performance affects the distribution of normative statuses among the participants in a dialogue and possibly other relevant agents. Presumptions, in turn, are typically characterized by reference to their normative effects: $(i)$ shifts of the burden of proof among the conversing agents and (ii) changes in the distribution of presumptive statuses attached to propositions put forth in a dialogue. Therefore, it is natural to treat them as moves made in illocutionary games and use the score-keeping model to track their dynamics.

As Godden and Walton (2007) rightly observe, the challenge to speech-act based models of presumptions is to specify the conditions under which an utterance put forth as a presumption is a correct conversational move or, more specifically, to identify the conditions that warrant the shift of the burden of proof that it attempts to produce as well as the presumptive status conferred on the proposition expressed by the speaker. The problem is, namely, that a crafty proponent who has the burden of proving the proposition that $p$ may attempt to put this proposition forward as a presumption, shift the burden of proof, and win on the cheap. A "strategic move" (Godden and Walton 2007, p. 343) of this kind gives rise to "petitio principii, the fallacy of circular reasoning or begging the question." (Walton 1993, p. 136) In a similar vein, Bermejo-Luque notes that "merely making a presumption cannot be enough for shifting the burden of proof" (Bermejo-Luque 2016, p. 6) and concludes that "it is not presumptions, but correct presumptions what may involve a privileged status within an argumentative exchange." (Ibid.) For her, to perform a mere presumption that $p$ is to mean or, more accurately, to speaker-mean "that it is reasonable to assume that p;" (Ibid., p. 9) to perform a correct presumption, by contrast, is to put forth the proposition that $p$ in circumstances in which it is in fact reasonable to assume that $p$. In his critical comment on Walton's speech-act model of presumptive statuses, Godden argues that "it is epistemically mistaken to introduce something to a dialogue on the support of an assumption (e.g., with agreement but without support) and then arbitrarily, or by dialectical fiat, assign to it some other epistemic standing;" (Godden 2017, p. 491) as he rightly observes, "[c]laims of the presumptive acceptability of [the proposition that] $p$ do not, typically, confer presumptive acceptability upon [the proposition that] p." (Ibid., p. 490)

In my view, however, the score-keeping model of presumptions enables us to meet the above-mentioned challenge. That is to say, it provides conceptual tools well-suited for describing the conditions under which an utterance that is put forth as a presumption constitutes or takes effect as a correct or appropriate act of presuming; in other 
words, it provides a sufficient basis for developing a theory of warranted presumptions: warranted shifts in burdens of proof and warranted presumptive statuses attached to propositions put forth in a dialogue. With this theory in hand, we will be able to identify "tricky, unperceived, and unlicensed shifts in a burden of proof in a speech act of presumption in dialogue" (Walton 1993: p. 137) and distinguish them from warranted changes in conversational obligations.

In sum, the model of presumptions as illocutionary acts presented in this section is expected to $(a)$ account for the dynamics of the shifts of the burden of proof in a critical discussion, $(b)$ specify the conditions under which these shifts are legitimate and warranted, $(c)$ model the dynamics of presumptive statuses attached to propositions put forth in a dialogue and $(d)$ describe conditions that warrant our jointly-made though defeasible decisions to proceed in argument as if certain propositions were true or justified.

\subsection{Individual presumptions}

Illocutionary act types can be distinguished by reference to their normative effects; i.e., by reference to how they modify the system of rights, entitlements, commitments and obligations of conversing agents. In most cases, the successful performance of a speech act - the performance that brings about an appropriate change in the nexus of normative relations among the relevant social agents-involves the action of an individual speaker only. In short, most illocutionary acts seem to be unilateral. As Searle claims:

The speech act scenario is enacted by its two great heroes, "S" and " $H$ "; and it works as follows: $\mathrm{S}$ goes up to $\mathrm{H}$ and cuts loose with an acoustic blast; if all goes well, if all the appropriate conditions are satisfied, if S's noise is infused with intentionality, and if all kinds of rules come into play, then the speech act is successful and nondefective. After that, there is silence; nothing else happens. The speech act is concluded and S and H go their separate ways (Searle 1992, p. 7).

Of course, hearers do contribute to the mechanism whereby unilateral speech acts take effect as felicitous illocutions of certain types. Nevertheless, what they contribute comes down to supplying uptake: to their recognition of "the meaning and of the force of the locution." (Austin 1975, p. 117) Apart from that, no further action on the part of the hearer seems to be required for the speaker's act to bring about its normative effect. For instance, the speaker's utterance of a sentence of the form 'I will do A" takes effect as a promise-it succeeds in producing the speaker's commitment to do $A$ as well as the hearer's right to expect the speaker to do $A$ and reproach her if she fails to discharge her commitment-provided the hearer takes the speaker's utterance to be a promise rather than, say, a prediction, a warning or a threat.

In some cases, however, the discursive mechanism responsible for modifying the nexus of interpersonal normative relations requires two complementary actions: one performed by the speaker and the other by the hearer. As Austin notes, "for a bet to have been made, it is generally necessary for the offer of the bet to have been accepted 
by a taker (who must have done something, such as to say 'Done').” (Austin 1975, p. 9) Betting, then, is a bilateral speech act: Its successful performance involves not only the securing of uptake on the part of the hearer, but also the hearer's complementary move that completes the pattern initiated by the speaker. In general, the successful performance of a bilateral speech act involves the reproduction of a complex pattern that involves the speaker's utterance of a certain sentence and the hearer's complementary response to it. ${ }^{14}$

In what follows, I take individual presumptions to be unilateral speech acts the central function of which is to shift the burden of proof among the conversing agents. As Cristina Corredor claims,

[a] presumption creates the obligation on the part of the addressee to give evidence or reasons for his opposition to endorse the presumption, whenever he or she does oppose it (Corredor 2017, p. 583).

What is more, I assume that an utterance put forth as an individual presumption succeeds in bringing about its normative effect understood as the reallocation of the burden of proof-and, by the same token, takes effect as a felicitous presumption-provided, first, it is issued with a required authority and, second, secures uptake on the part of the respondent. If issued without the required authority, then, it fails to constitute a felicitous presumption and as such should be described as an Austinian misfire, an act "purported but void."15 (Austin 1975, p. 18) Roughly speaking, the speaker's authority to perform a felicitous act of presuming that $p$ - which is part of the source score representing the context in which her utterance is made-consists in her cognitive accessibility to "the grounding that supports the presumption;" (Corredor 2017, p. 282) in other words, the speaker's utterance takes effect as a felicitous individual presumption provided her epistemic situation is such that, should the need arise, she could justify the proposition that $p$ by further arguments or at least make a reliable effort to collect new evidence in support of it. (It remains to be examined, however, what it is for the proponent to have cognitive access to the grounding supporting her presumption and under what conditions her effort or attempt to collect new supporting evidence can be regarded as 'reliable.' I return to discussing these issues in the final paragraphs of this subsection.) Her utterance secures uptake on the part of the respondent, in turn, if he takes it to be a felicitous or appropriate presumption (which does not amount to endorsing the presumed proposition).

In my view, the normative effect of making an individual presumption-which is registered by the target score of conversation-goes beyond committing the hearer to give a reason if he refuses to endorse the proposition expressed by the speaker. If felicitously performed-if issued by a speaker who is endowed with the required authority represented as a source score component—it brings about a number of normative effects characteristic of assertion and its kin: it entitles the hearer to endorse

\footnotetext{
14 The idea of using speaker-hearer patterns to account for the dynamics of speech acts comes from Ruth G. Millikan; see Millikan (2005), cf. Witek (2015a, 2019b).

15 Unlike Bermejo-Luque (2016, pp. 6-7) and in agreement with the Austinian approach to speech act theory, then, I stipulate that what she calls 'incorrect presumptions' or 'mere presumptions' are not presumptions at all.
} 
the proposition, puts him under an obligation to correct the speaker if he has strong evidence that the proposition she expresses is false, and creates the speaker's obligation to withdraw her endorsement if presented with sufficiently strong evidence that the proposition she expresses is false. In what follows, however, I assume that the reallocation of the burden of proof is a key aspect of the normative effect that the act of making a presumption has on the context of its performance; in other words, it is what makes presumptions unique speech acts different from other assertives. I also argue that the shift can be achieved either by illocution or by accommodation.

In the remainder of this subsection, I proceed as follows. First, I focus on individual presumptions that are performed directly, i.e., at the level of what is illocuted rather than accommodated. Next, I move to discussing cases of individual presumptions performed indirectly, i.e., at the level of what is accommodated. Finally, I elaborate on the idea of warranted shifts in the burden of proof; more specifically, I offer the notion of the speaker's procedure-based authority presupposed or required by the felicity of her act of presuming.

One example of an individual presumption performed directly comes from Cristina Corredor, who considers the following talk-exchange:

(11) $A$ : a. Do you think it a wise idea to let $C$ to manage the accounts?

$B$ : b. $C$ has the required expertise.

c. Besides, I presume his honesty.

A: d. I wouldn't,

e. remember that in his previous position as a bookkeeper disciplinary proceedings were opened against him that haven't yet been closed.

(Corredor 2017, p. 585)

According to Corredor (2017, p. 586), the mechanism whereby speaker B's utterance of (11c) takes effect as a successful presumption-bringing about an intended change in the distribution of the burden of proof among $A$ and $B$-involves accommodation. In my view, however, it involves illocution and relevant rules of illocutionary dynamics: The reallocation of the burden of proof is not accommodated, but illocuted.

As Austin noted, the successful performance of an illocutionary act has three types of effects. First, $\left(e_{1}\right)$ it secures uptake on the part of the hearer, which normally "amounts to bringing about the understanding of the meaning and of the force of the locution." (Austin 1975, p. 117) Second, $\left(e_{2}\right)$ the act takes effect by bringing about changes in the domain of normative or institutional facts such as commitments, obligations, rights, entitlements, and so on. Third, $\left(e_{3}\right)$ "many illocutionary acts invite by convention a response or sequel. Thus an order invites the response of obedience and a promise that of fulfilment." (Ibid., the emphasis in italics is mine-M.W.) In other words, the successful act initiates the reproduction of a conversational sequence or pattern and, at the same time, invites the hearer or other participants in a dialogue to complete it. It is instructive to note that the three types of effect, though different, are related to each other: Normally, the hearer's response invited by the speaker's act manifests his uptake; quite often, the hearer who produces the invited response can be adequately described either as discharging the obligation or exercising the right 
brought about by the speaker's act; finally, unless uptake is secured, the speaker's act cannot be regarded as bringing about its normative effects. For instance, in uttering (11c), speaker $B$ performs a direct act of making a presumption that not only shifts the burden of proof among the participants in the dialogue, but also invites speaker $A$ either to endorse the proposition that $C$ is honest $o r$ to refuse to endorse it and, next, justify his refusal. In other words, the response that $B$ 's utterance invites by convention qua a felicitous presumption-where 'by convention' is to be read as 'in accordance with a relevant pattern of verbal interaction' (see Witek 2015a, 2019b) —is either A's endorsement of the proposition in question or his refusal to do so followed by an appropriate justification, e.g., $A$ 's utterances of (11d) and (11e), respectively. In general, the proponent's successful individual presumption that $p\left(e_{2}\right)$ creates the obligation on the part of the respondent to justify his refusal to endorse the proposition that $p$, whenever he refuses to endorse it, and, at the same time, $\left(e_{3}\right)$ invites him to complete one of the conversational sequences: "the proponent's presumption that $p$ followed by the respondent's endorsement of the proposition that $p$ " or "the proponent's presumption that $p$ followed by the respondent's refusal to endorse the proposition that $p$ and his justification of this refusal."

It is instructive to note that even though speaker $A$ refuses to endorse the proposition that $C$ is honest, he takes the utterance of $(11 \mathrm{c})$ to be a felicitous presumption. That is to say, he completes an appropriate pattern of verbal interaction which involves the speaker's public endorsement of a claim and the hearer's refusal to endorse it followed by a required justification. In other words, the sequence of conversational moves made in uttering (11d) and (11e) constitutes a response invited by $B$ 's act made in uttering (11c) and, at the same time, manifests $A$ 's implicit uptake. In short, uptake has been provided and, provided $B$ has the procedure-based authority to perform felicitous presumptions about $C$, the utterance of (11c) has taken effect as a felicitous act of presuming.

The above-used notion of procedure-based authority is explained in the final paragraphs of this subsection. For the purposes of the present discussion, it suffices to note that in providing and manifesting his uptake, speaker $A$ takes for granted that speaker $B$ is endowed with the required "authority or authoritativeness;" (Corredor 2017, p. 586) i.e., he takes her to be entitled to perform the act of presuming that $C$ is honest. More specifically, the felicity of this act presupposes that $B$ is appropriately related to $C$; i.e., that she has a sufficient acquaintance with him, meets him more or less regularly, has heard a lot of good things about him, etc. In other words, an Austinian presupposition of $B$ 's act is her epistemic situation that entitles her to endorse certain opinions about $C$ and provides access to evidence she might use to support her claim if it is challenged.

By contrast, let us consider the following variant of the dialogue between $A$ and $B$ :

(12) $A:$ a. Do you think it a wise idea to let $C$ to manage the accounts?

$B$ : b. $C$ has the required expertise.

c. Besides, I presume his honesty.

$A$ : d. You know nothing about $C$ ! 
One can say that in uttering (12d), $A$ refuses to endorse the opinion expressed by $B$. In my view, however, the conversational move made in $(12 \mathrm{~d})$ can be better understood as defusing the purported presumption made in uttering (12c) by explicitly blocking or even rejecting the accommodation of what the act's felicity presupposes in Austin's sense. In other words, $A$ claims that $B$ does not have the required authority: Her current epistemic situation does not entitle her to express and endorse opinions about $C$ and his honesty.

In uttering (11d) and (11e), $A$ refuses to adopt $B$ 's point of view, but takes her utterance to be a binding presumption that invites him to justify his refusal. In other words, $A$ acknowledges that $B$ 's utterance is issued with appropriate authority and, as a result, takes effect as a felicitous presumption. At the same time, however, he reckons that what $B$ says - the proposition communicated and endorsed by her-fails to meet what Sbisà (2019) calls 'objective requirements;' i.e., that the opinion that $C$ is honest does not fit or correspond to the facts. In uttering (12d), by contrast, $A$ declines to regard $B$ 's utterance as a felicitous presumption; i.e., as an act made with the required illocutionary authority. Consequently, $A$ can also be said to refuse to endorse the opinion expressed by $B$. Nevertheless, the primary goal behind his utterance of (12d) is to attack $B$ 's authority to put forth her utterance as a reasonable endorsement ${ }^{16}$; in other words, $A$ 's primary focus is on the conditions under which $B$ 's utterance can be regarded as a felicitous illocution rather than on the objective requirements pertaining to what she says.

Let us now turn to a discussion of individual presumptions performed indirectly. In my view, quite often we perform back-door presumptions that involve the accommodation of contents associated with the use of so-called presupposition triggers. Let us consider, namely, cases of direct presumptions which express propositional contents by means of presupposing sentences; i.e., by sentences containing presupposition triggers such as definite descriptions, factive verbs, possessive nominal phrases, change of state verbs, and so on. Let us assume that normally-in the course of a standard communicative practice-using sentence ' $p$ ' to say something involves or commits one to presupposing that $q$; for instance, in normal conversational conditions, saying that the present king of France is bald involves presupposing that France has a king. My hypothesis is that in presuming that $p$, a speaker implicitly presumes that $q$. For instance, in uttering (13a), the speaker makes an implicit presumption to the effect that France has a king; by the same token, in uttering (14a), she indirectly presumes that Sue bought a ferret.

(13) a. I presume that the present king of France is bald.

b. France has a king.

(14) a. I presume that Sue regrets that she bought a ferret.

b. Sue bought a ferret.

I do not want to argue that the presuppositions (13b) and (14b) of the clause complements of (13a) and (14b), respectively, survive the embedding or, more specifically,

\footnotetext{
16 The conversational move made in uttering (12d) can be described as involving the rhetorical technique, ad hominem; for a speech act-based model of ad hominem, see Budzyńska and Witek (2014).
} 
that they project from under the scope of the 'I presume that' operator. My point, rather, is that the set of one's presumed or rationally embraced propositions is closed not only under entailment, but also under the relation of presupposing: in saying 'I presume that $p$,' the speaker not only invites the hearer to endorse the proposition that $p$, but also to accommodate her presumption that $q$, where ' $q$ ' expresses what saying that $p$ normally presupposes.

In the above discussion of direct and indirect individual presumptions I have used an intuitive notion of presumption-licensing authority construed as the proponent's power or entitlement to issue felicitous presumptions on certain issues. To perform a felicitous presumption that $p$ is to succeed in creating the warranted shift in the burden of proof with respect to the proposition that $p$. It remains to be considered, then, what constitutes its status as a felicitous presumption. In first approximation, we can assume that what makes it reasonable or correct for me to put forth the proposition that my colleague is honest as a felicitous presumption is my current epistemic situation in virtue of which I'm not only entitled to express certain opinions about him, but also have access to evidence that may be used to increase the credibility of my claims whenever they are challenged; in other words, the source of my presumption-licensing authority is the fact that, first, I have known my colleague for a long time as well as heard a lot of things about his deeds and, second, that I am in a position to collect new direct and indirect evidence about his honesty. One can ask, however, what distinguishes presumptions from assertions, since my epistemic situation described above seems to provide sufficient grounds for my making a tentative assertion about my colleague's honesty, too. ${ }^{17} \mathrm{My}$ initial response to this question is that presumptions, in contrast to mere assertions, are made to provide premises for current reasoning or, more specifically, to provide premises without which we would not be able to proceed with our inquiry. Therefore, my act of presuming and the shift in the burden of proof it gives rise to is warranted by certain aspects of my current cognitive as well as conversational situation. What is more, the aspects in question constitute the appropriateness conditions for presumings and as such are to be represented in the source score of a conversation. In the remainder of this subsection I elaborate on this idea in more detail.

Let us consider a type of language game that, in my view, involves clear and uncontroversial examples of presumptions: The Popperian game of testing and falsifying scientific hypotheses by putting forth and accepting the so-called basic statements. By way of illustration, let us consider a situation in which researcher $R_{1}$, after appropriately performing a relevant empirical test, puts forth a basic statement of the form " $P(a) \& \sim Q(a)$ " with an intention to falsify hypothesis " $\forall x(P(x) \rightarrow Q(x))$ " proposed by researcher $R_{2}$. Statement " $P(a) \& \sim Q(a)$ " is a potential falsifier of $R_{2}$ 's hypothesis, since it contradicts prediction " $P(a) \rightarrow Q(a)$ " that can be inferred from it. From the logical point of view, however, falsification is never conclusive (Popper 2005, p. 19): $R_{2}$ may attempt to evade falsification and save his hypothesis "by any kind of conventionalist stratagem" (Ibid., p. 61): He may, first, introduce ad hoc an auxiliary hypothesis that has no independently tested consequences but merely serves "to restore the agreement between theory and experiment;" (Ibid., p. 62) second, he may modify

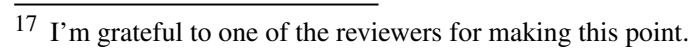


ad hoc the so-called ostensive definitions of predicates " $P$ " and " $Q$ "; third, he may adopt a sceptical attitude towards the reliability of $R_{1}$ ("he is a liar") and his findings ("they are insufficiently supported, unscientific, or not objective"); finally, he may cast doubts on the acumen of the theoretician involved in making the test. From the logical point of view, in short, no basic statement can be conclusively corroborated and treated as an ultimate statement in science. In general, no statement can be justified by experience. "Statements can be logically justified only by statements." (Ibid., p. 21). Theoretically, then, every basic statement can be questioned and tested ad infinitum.

According to Popper, however, falsification is not a logical fact; rather, I would say, it is an institutional event that comes into existence or takes effect in virtue of a collective and warranted agreement among the participants in a scientific inquiry. What makes this agreement warranted - for instance, what warrants their joint decision to accept basic statement " $P(a) \& \sim Q(a)$ " as a falsifier of " $\forall x(P(x) \rightarrow Q(x))$ " - is the fact that it has been made in conformity with the scientific procedure or method. The procedure involves, first, "methodological rules for the acceptance of basic statements" (Ibid., p. 67) and, second "methodological rules which prevent the adoption of conventionalist stratagems" (Ibid., p. 62) and exclude "those ways of evading falsification which (...) are logically possible." (Ibid., p. 20) The rules of these two types make research practice possible; in other words, they are constitutive with respect to scientific inquiry and the communicative practice it involves. As Popper claims:

For any basic statement can again in its turn be subjected to tests, using as a touchstone any of the basic statements which can be deduced from it with the help of some theory, either the one under test, or another. This procedure has no natural end. Thus if the test is to lead us anywhere, nothing remains but to stop at some point or other and say that we are satisfied, for the time being. It is fairly easy to see that we arrive in this way at a procedure according to which we stop only at a kind of statement that is especially easy to test. For it means that we are stopping at statements about whose acceptance or rejection the various investigators are likely to reach agreement. And if they do not agree, they will simply continue with the tests, or else start them all over again. If this too leads to no result, then we might say that the statements in question were not inter-subjectively testable, or that we were not, after all, dealing with observable events. If some day it should no longer be possible for scientific observers to reach agreement about basic statements this would amount to a failure of language as a means of universal communication. It would amount to a new 'Babel of Tongues': scientific discovery would be reduced to absurdity (Ibid., p. 86).

In my view, in putting forth the basic statement that $p$ with the intention to falsify $R_{2}$ 's hypothesis, researcher $R_{1}$ makes an individual presumption that $p$. (She also initiates a conversational sequence that, when appropriately completed by $R_{2}$, constitutes a successful act of joint presumption; I return to discussing this issue in Sect. 3.2.) What makes her utterance a correct move in an inquiry is her current epistemic and conversational situation. First, she finds herself in a situation in which " $P(a) \& \sim Q(a)$ " is easily and intersubjectively testable; that is to say, to test this statement she uses commonly accepted semantic and empirical criteria for predicates " $P$ " and " $Q$ " and 
follows shared methodological standards designed to minimize the risk of influencing the outcome of her experiment by unknown and uncontrolled factors. Second, if challenged, she is in a position to use the same standards to collect further data so as to confirm or disconfirm her statement; in short, should the need arise, she may continue with the tests. Third, the point behind her statement is to address what can be called, following Roberts (2015) and other scholars working within the information structure, the current question under discussion; more specifically, to proceed with their inquiry-i.e., to decide whether they should accept $R_{2}$ 's hypothesis $-R_{1}$ and other researchers need a basic statement that might play the role of a potential falsifier. Fourth, $R_{1}, R_{2}$, and other relevant participants in this inquiry are 'Popperian agents' in that they share the goal of approaching the truth and are aware of the fact that from the logical point of view falsification is never conclusive. In sum, the four conditions listed above can be regarded as appropriateness conditions for basic statements construed as individual presumptions. In other words, they are presupposed by the felicity of $R_{1}$ 's speech act made in uttering " $P(a) \& \sim Q(a)$ " and as such can be represented by the source score that corresponds to the context in which $R_{1}$ 's utterance is made. What is more, they are determined by the relevant "accepted conventional procedure having a certain conventional effect, that procedure to include the uttering of certain words by certain persons in certain circumstances." (Austin 1975, p. 14) In the case under discussion, the conventional effect of $R_{1}$ 's utterance is the transfer of the burden of proof from $R_{1}$ to $R_{2}$.

It is instructive to stress that the first two conditions enable us to define "the speaker's cognitive accessibility to the source of authority (...) that supports the presumption" (Corredor 2017, p. 582) by reference to the procedures of scientific inquiry; namely, the rules and standards constituting the procedure invoked by $R_{1}$ give her cognitive access to evidence that can be used to confirm or disconfirm her statement. The third condition concerns the conversational situation in which the speaker finds herself in. The fourth condition, in turn, concerns the researchers' mutually shared methodological attitudes. If these conditions are jointly satisfied, $R_{1}$ 's basic statement takes effect as a binding and warranted individual presumption: It succeeds in producing $R_{2}$ 's obligation to justify his refusal to accept " $P(a) \& \sim Q(a)$ " as a potential falsifier of his hypothesis or, more precisely, to his obligation to justify it without resorting to conventionalist stratagems.

The four conditions listed above-and, in particular, the notions of procedure-based cognitive accessibility and procedure-based authority they define-can be generalized so as to apply to other types of discourse. Let us reconsider, for instance, dialogue (11) discussed above. In uttering (11c), $B$ performs a correct act of presuming that results in the warranted shift in the burden of proof or, in other words, in conferring on $A$ the burden of disproof. First, $B$ finds herself in a situation in which her opinion-which is based on her personal experience-is easily and intersubjectively testable; that is to say, in putting forth (11c) as a reasonable endorsement, speaker $B$ uses collectively accepted semantic and empirical criteria for predicate 'honest.' Second, should the need arise, she is in a position to use the same criteria to collect further data so as to confirm or disconfirm her opinion. Third, she utters (11c) to address the current question under discussion; more specifically, the point behind her utterance is to provide a premise to be used to decide whether it is wise to let $C$ to manage the 
accounts. Fourth, $A$ and $B$ are critical and rational agents in that they share the goal of reaching rationally acceptable conclusions and are aware of the fact that no opinion based on personal experience is conclusive. If the above-mentioned conditions are met, $B$ is in a position to presume - rather than, say, assert - that $C$ is honest.

What is more, to assume that $A$ and $B$ are critical and rational agents is, inter alia, to expect $A$ not to use conventionalist stratagems. In particular, it is to expect him to justify his refusal to endorse the proposition put forth by $B$ rather than to utter (11d) alone. Of course not every stratagem is conventionalist and incorrect. It is an open option for $A$, for instance, to utter "Why presume $C$ 's honesty?" and thereby demand of $B$ that she give reason for her opinion expressed in (11c) and even block in Langton's sense (see the discussion in Sect. 2.3) B's implicit attempt-implicit in that it employs the back-door method-to get the conversing participants to think that she has the authority to presume that $C$ is honest; this move, however, is legitimate only if $A$ has no access to the grounding that supports $B$ 's presumption.

Presumably, the proposed set of four appropriateness conditions is not complete. In particular, more has to be done to link the proposed requirements to the ends of truth (Popper 1962, 2005) or rational acceptability (Putnam 1981). However, a detailed elaboration of this topic — which has been extensively discussed in the modern philosophy of science-goes beyond the scope of the present paper. For the present purposes it suffices that the proposed set of appropriateness conditions offers a template on which further analysis may be undertaken. What is more, it is intended as an amendment to the set of speech act conditions proposed by Walton (1993) in "The Speech Act of Presumption." Finally, it enables us to (a) account for the dynamics of the shifts of the burden of proof in a critical discussion, $(b)$ specify the conditions under which these shifts are legitimate and warranted and, by the same token, answer the question posed at the begging of this section: What is it for the proponent to have cognitive access to the grounding supporting her presumption and what are the conditions under which her effort to collect new supporting evidence is reliable? At the same time, they enable us to define the notion of warranted presumption and explain the difference between warranted and "tricky, unperceived, and unlicensed shifts in a burden of proof in a speech act of presumption in dialogue." (Walton 1993: p. 137) One example of such a tricky presumption can be a conversational move made in uttering "I presume that the Holocaust never happened; correct me if I'm wrong." (Freeman 1996, p. 289; cf. Bermejo-Luque 2016, p. 6) In putting forth such an utterance as a presumption, the speaker makes an unwarranted attempt to shift the burden of proof. It is unwarranted, because the speaker's opinion under discussion is not easily testable in the situation she finds herself in; what is more, it does not provide a premise to be used to address the current question under discussion but, rather, is an attempt to decide the question on the cheap by conferring the burden of disproving the speaker's opinion on her interlocutors.

\subsection{Joint presumptions}

The performance of a joint presumption involves two complementary actions of at least two agents who are engaged in reproducing a pattern of verbal interaction. Nor- 
mally, the pattern involves the speaker's individual presumption and the addressee's endorsement of the opinion expressed by the speaker. If performed completely, the bilateral act of jointly presuming that $p$ results in contributing the proposition that $p$ to the common ground among the interacting individual agents; i.e., to the set of propositions they mutually accept for their current conversational purposes (Stalnaker 2002). More accurately, its illocutionary point is to modify the score of the conversation by conferring on the proposition that $p$ the normative status of jointly "recognised though tentative acceptability" (Lewiński 2017, p. 592)—or, to put it in different terms, of jointly recognized mutual endorsement - in virtue of which the speaker and the hearer are entitled to use this proposition as a premise in their further reasoning.

By way of illustration, let us consider once again dialogue (11) from the previous subsection. The move made in uttering (11c) constitutes a felicitous individual presumption that modifies the network of normative relations between $A$ and $B$. In particular, it ( $a$ ) takes effect by transferring the burden of proof from $B$ to $A$ and (b) invites $A$ to endorse the proposition expressed by $B$. Nevertheless, the conversational sequence it initiates fails to constitute a successful joint presumption: Speaker $A$ explicitly refuses to endorse the proposition he is invited to accept. For comparison, let us consider the following variant of the dialogue between $A$ and $B$ :

(15) $A$ : a. Do you think it a wise idea to let

$C$ to manage the accounts?

$B$ : b. $C$ has the required expertise.

c. Besides, I presume his honesty.

A: d. OK. (Corredor 2017, p. 585)

The conversational move made in uttering (15c) not only takes effect as a felicitous individual presumption, but also gives rise to a conversational sequence that constitutes a successful joint presumption. That is to say, besides bringing about a change in the distribution of the burden of proof among $A$ and $B$, it also results in getting $A$ to endorse $B$ 's opinion about $C$ 's honesty. As a result, the bilateral act constituted by sequence $\langle(15 \mathrm{c}),(15 \mathrm{~d})\rangle$ succeeds in conferring on the proposition expressed by $B$ the normative status of jointly recognized mutual endorsement-the jointly presumptive status, for short-in virtue of which $A$ and $B$ are entitled to use the proposition in question as a premise in further reasoning as well as to expect each other to accept its employment in the discursive practice of giving reasons as correct play.

Both individual and joint presumptions affect the conversational score. The former changes the distribution of the burden of proof among the conversing agents, thereby modifying the network of normative relations between them. The latter updates the system of mutually endorsed propositions-propositions with the normative status of jointly recognized mutual endorsement - thereby making certain subsequent speech acts appropriate conversational moves. The illocutionary point of individual presumptions is to reallocate the burden of proof. The proper function of joint presumptions construed as bilateral speech acts is to allow the conversing agents to use certain propositions as acceptable premises despite the absence of conclusive evidence in favour of them; generally, it is to allow them "to proceed when relevant evidence or information is missing" (Lewiński 2017, p. 592). 
Let us now turn to discussing joint presumptions whose performance involves the back-door method. Recall, for instance, that a speaker who utters (14a) can be regarded as performing two individual presumptions: one direct ("Sue regrets that she bought a ferret") and the other indirect ("Sue bought a ferret"). In my view, both the former and the latter can-but do not have to-give rise to successful joint presumptions. By way of illustration, let us consider the following dialogue ${ }^{18}$ :
(16) $A:$ a. I presume that Sue regrets that she bought a ferret.
$B$ : b. I wouldn't.
c. I have heard that she bought an ostrich,
d. and that she regrets buying that!

Let us assume that $A$ 's utterance of (16a) counts as the felicitous performance of two individual presumptions - one direct, and the other indirect-but fails to constitute the corresponding two joint presumptions the point of which is to update the system of mutually endorsed propositions with "Sue regrets buying a ferret" and "Sue bought a ferret," respectively: The former (i.e., the presupposing proposition) cannot be endorsed because in uttering (16c) speaker $B$ justifies her refusal to endorse the latter (i.e., the presupposed proposition).

It remains to be examined what warrants the jointly presumptive status conferred on propositions put forth in a dialogue. To this end, let me recall that the successful individual presumption that $p$ both $\left(e_{2}\right)$ creates the obligation on the part of the respondent to justify his refusal to endorse the proposition that $p$, whenever he refuses to endorse it and $\left(e_{3}\right)$ invites him to complete one of the conversational sequences: "the proponent's presumption that $p$ followed by the respondent's endorsement of the proposition that $p$ " or "the proponent's presumption that $p$ followed by the respondent's refusal to endorse the proposition that $p$ as well as his justification of this refusal." Unlike the latter, the former constitutes a successful joint presumption that results in conferring the jointly presumptive status on the proposition that $p$. The status exists in virtue of being jointly agreed by the proponent, the respondent and other relevant participants in a dialogue. It is warranted, in turn, if the agreement in question has been reached by abiding by the appropriate standards and procedures akin to the Popperian system of methodological rules for the acceptance of basic statements and rules which prevent the adoption of conventionalist stratagems (see the discussion in Sect. 3.1). Roughly speaking, if an utterance put forth as an individual presumption is issued with the required procedure-based authority - that is to say, if it takes effect as a warranted individual presumption-and, next, is completed by the respondent's procedurally correct act of embracing the presumed proposition, then the resulting sequence constitutes a warranted joint presumption.

\subsection{Collective presumptions}

The score-keeping model of illocutionary games presented in Sect. 2 allows us to define a third category or type of presumption which, for reasons explained below, can be

$\overline{18}$ I'm grateful to one of the reviewers for helping me to clarify this example. 
called 'collective.' Collective presumptions are back-door speech acts. That is to say, the mechanism underlying their performance involves accommodation. They operate in the background by exploiting rules and standards specifying conditions under which currently performed direct illocutionary acts can be regarded as correct play. Roughly speaking, to perform an indirect or back-door collective presumption in making a direct or official speech act of a certain type-e.g., a testimony, a statement, an order, a permission, and so on-is to contribute to sustaining, establishing or modifying the practice to which the official act outsources (Langton 2015) or defers (Corredor 2017) its authority.

According to Austin, the felicity of an illocutionary act presupposes, first, that there exists "an accepted conventional procedure having a certain conventional effect, that procedure to include the uttering of certain words by certain persons in certain circumstances" (Austin 1975, p. 20), and, second, that "the particular persons and circumstances in a given case must be appropriate for the invocation of the particular procedure invoked." (Ibid., p. 21) In short, there seem to be at least three types of Austinian presuppositions: procedural (that there exists "an accepted conventional procedure"), personal (that "the particular persons [...] in a given case" are appropriate), and circumstantial (that "the particular [...] circumstances in a given case" are appropriate). So far, we have focused on the accommodation of personal Austinian presuppositions; e.g., on accommodating the speaker's authority to issue the act she is taken to make. A central idea behind the proposed account of collective presumptions is that procedural presuppositions can be accommodated, too. That is to say, a speaker who performs the official act of $F$-ing presumes - at the level of back-door acts - that a certain procedure for $F$-ing is collectively accepted in her community. The indirect presumption in question is performed by an individual agent and takes effect provided nobody blocks it by saying, "Hey, wait a minute, $F$-ing is not something you can do with words." What makes it collective is the peculiar nature or status of the conventional object it affects. The act under discussion sustains, modifies or determines more precisely the procedure it invokes. In other words, it specifies in more detail the system of collectively accepted rules, patterns, standards and scripts the reproduction of which counts as or constitutes its felicitous performance.

It is instructive to stress that the proposed distinction between joint and collective presumptions is, to some extent, modelled on the contrast between joint and collective intentionality drawn by Michael Tomasello in A Natural History of Human Thinking (Tomasello 2014): Roughly speaking, joint intentionality pertains to goals shared by a limited number of cooperating agents, whereas the objects of collective intentionality are collectively accepted and culturally created norms, rules and standards. To call certain conversational phenomena 'joint' and 'collective' acts of presuming, therefore, is not to assume that they are performed by joint or collective agents, respectively. Every act of making a joint or collective presumption involves the cooperation of individual agents only. It is called 'joint' or 'collective' to reflect the nature of its conventional effects.

The idea of accommodating procedural presuppositions is akin to Langton's (2015) notion of outsourcing the authority of an act to a social practice. By way of illustration, let us consider a situation in which a father says to his son: 
(17) Boys do not cry.

According to Langton (2015, p. 23), it is natural to assume that the primary goal behind this utterance is to get the boy to change his current behaviour. In other words, in uttering (17) the father performs a directive act the essential effect of which is to put his son under obligation to stop crying. The felicity of this directive requires-it presupposes, in Austin's sense- that it is issued with an appropriate authority. Generally, the authority of an act can be either derived from the authority of the speaker or outsourced to a social practice. In the case under discussion, it can be said to be outsourced to a regularity ('Most boys do not cry'), or to a cultural norm ('Boys do not cry'). ${ }^{19}$

It is instructive to note that the regularity to which the father outsources the authority of his directive act is not a conventional procedure for the performance of speech acts. In my view, then, it does not involve the accommodation of procedural Austinian presuppositions. ${ }^{20}$ In some cases, however, the speaker can defer the felicity of her acts to a discursive practice within which the acts counts as correct play. For instance, when apologizing to the American people for his comments about kissing and touching women without consent, Donald Trump said:

(18) It's just locker-room talk.

thereby referring to a discursive practice of 'locker-room talk' where his previous conversational behaviour had allegedly been acceptable (Langton 2015, p. 8). In other words, by uttering (18) he attempted to use a back-door method to invoke, sustain or presume a collectively accepted procedure for performing acts of subordinating women.

The above-discussed act of invoking the practice of 'locker-room talk' is an illustrative, though not typical, example of what I call 'collective presumptions.' Most collective presumptions do not involve the use of presuppositional triggers, such as definite descriptions, to refer to sustained or invoked practices. What they involve, rather, is accommodating Austinian procedural presuppositions. By way of illustration, let us consider once again the desert island scenario in which Jones utters to Smith sentence (2). Through accommodation of personal presuppositions, he establishes his authority over Smith and other survivors. Through accommodation of procedural presuppositions, in turn, he invokes the practice or procedure of giving and following orders and contributes to its establishment on the desert island, thereby sustaining its continuous existence.

By analogy, let us consider a court discussion in which one of the lawyers utters sentence (19) or (20):

(19) He should be regarded as innocent.

(20) From a legal point of view, he is innocent.

\footnotetext{
19 I am grateful to one of the reviewers for drawing my attention to the latter possibility. In a similar vein, Langton considers the possibility of outsourcing the authority under discussion to an ideal ('Those who fulfil the ideals for boys don't cry'), which "is Sarah Jane Leslie's interpretation of this particular generic." (Langton 2015: p. 23)

20 As one of the reviewers noticed, however, it is possible to argue that it involves the accommodation of a cultural norm.
} 
thereby making an individual presumption to the effect that the defendant is to be regarded as innocent. It is instructive to note, however, that in performing this act, she invokes and sustains the general rule that one has to be regarded as innocent until proven guilty. What is more, if the case she considers is not typical, the participants in the court discussion have to decide whether the rule applies to it or not; in other words, the utterance of (19) or (20), provided it takes effect as a successful collective presumption, specifies the invoked procedure in more detail. As Marina Sbisà notes, Austinian conventional procedures for the performance of illocutionary acts should be viewed as incomplete and open-ended systems akin to Gestalt-like patterns (Sbisà 2009, p. 48) which, pace Searle (1969), cannot be exhaustively represented as complete lists of rules (Sbisà 2019, p. 26, cf. Witek 2019a, p. 186). The act of invoking a procedure, then, involves something more than mere reproduction. What it involves, namely, can be described as filling gaps in the reproduced pattern or specifying it in more detail. The same holds for other types of illocutionary acts: verdicts, orders, promises, congratulations, rule enactments, and so on. Normally, in performing a speech act of a certain type, we perform a back-door speech act of collective presumption; that is to say, we presume, first, that there is a collectively accepted procedure for its performance and, second, that the procedure applies to the current case. In doing this, we sustain, modify and specify the pattern in more detail.

\section{Concluding remarks}

My aim in this paper has been to develop a score-keeping model of presumptions. To this end, I have presented the central tenets and distinctions of the score-keeping model of illocutionary dynamics and used them to distinguish between three types of presumptions construed as conversational moves. In doing this, I have adopted the speech-act based approach to presumptions, according to which presumptions are to be viewed as speech acts rather than propositional attitudes or propositions expressed in a discourse.

In particular, I have shown that the score-keeping model of illocutionary games, which provides conceptual tools for tracking the dynamics of discursive obligations and presumptive statuses, is also well-suited for describing conditions under which presumptions are warranted conversational moves. More specifically, the model of presumptions offered in this paper meets the following desiderata: It $(a)$ accounts for the dynamics of the distribution of the burden of proof among the participants in a critical discussion, $(b)$ specifies the conditions under which the burden-shifts are legitimate and warranted, $(c)$ tracks the dynamics of presumptive statuses conferred on propositions in a dialogue, and $(d)$ describes conditions under which the statuses are warranted. To meet requirements $(b)$ and $(d)$, I have proposed the notion of procedurebased authority that entitles the proponent to perform warranted presumptions; more specifically, I have argued that the proponent's presumption-licensing authority can be defined along the Popperian lines, i.e., in terms of the procedures for rational inquiry. A central idea behind the proposed theory of warranted presumptions, then, is that presumings construed as speech acts are not performed in the void; pace Godden (2017, p. 491), their normative effects are not created by a dialogical or illocutionary 
fiat. More specifically, warranted presumptions are issued in certain epistemic and conversational circumstances that are defined by the procedure of rational inquiry.

Most importantly, I have put forth and defended two hypotheses.

According to the first hypothesis, presumptions understood as speech acts can be grouped into three illocutionary act types defined by reference to the effects they have on the context of their production or, more precisely, by reference to how they affect the score of a conversation: (i) individual presumptions, (ii) joint presumptions, and (iii) collective presumptions. Correspondingly, we can distinguish between three components of conversational score that represent the effects of these acts, respectively: (i) the allocation of the burden of proof among the conversing parties, (ii) the system of jointly endorsed propositions that provide premises and principles to be used in further reasoning, and (iii) the system of collectively accepted standards, rules, and procedures that make the conversational activity possible and to which the conversing agents outsource or defer the felicity of their speech acts.

According to the second hypothesis, the functioning of presumptions involves two types of mechanisms: the direct mechanism of illocution and the indirect mechanism of accommodation. I have argued, pace Lewis (1979) and Langton (2015), that accommodation construed as a context-repairing process is not responsible for the production of the essential effects of speech acts. The latter are illocuted rather than accommodated; more specifically, they are produced by prospective mechanisms of illocution that make use of rules of direct dynamics rather than by retroactive mechanisms of accommodation that operate against the background of appropriateness rules. In particular, I have argued that individual and joint presumptions, though normally performed at the level of what is illocuted, may sometimes be performed by using the back-door method that exploits the mechanism of accommodating Stalnakerian presuppositions; in other words, even though I make room for accommodating mechanisms in the proposed model of presumptions, I do not embrace the view I have called panaccommodationalism about illocutionary acts. Collective presumptions, in turn, are back-door speech acts performed by exploiting the mechanism of accommodating procedural Austinian presuppositions, e.g., by modifying and sustaining collectively accepted procedures to which speakers outsource (Langton 2015) or defer (Corredor 2017) the felicity of their officially made acts.

By way of conclusion, I would like to use the proposed account to discuss some issues raised by three speech-act based models to be found in the literature: Walton's (1993) theory of presumptions as speech acts, Bermejo-Luque's (2016) account of presumptions as constatives in Bach and Harnish's (1979) sense, and Corredor's (2017) model of presumptions as Austinian verdicitives.

It is instructive to stress, first, that the set of four appropriateness conditions for presuming offered in Sect. 3.1 is designed as an amendment to Walton's set of speech act conditions for presumptions (Walton 1993, pp. 139-140; cf. Godden and Walton 2007, pp. 327-328). What is more, it enables us to define the difference between correct and incorrect presumptions - or, in other words, between warranted and 'tricky' shifts in the burden of proof - and thereby to resist scepticism about the adequacy of speechact based models of presumptions (see Walton and Godden 2007, p. 343; Godden 2017, pp. 490-491; see also the introductory paragraphs of Sect. 3). What is more, the score-keeping model provides conceptual tools that may be used to account for the 
mechanism behind the rhetorical strategy of making 'tricky' shifts in the burden of proof. By way of illustration, let us consider the following problem originally posed by Richard Whately and discussed by Walton:

imagine a case where a person who, confronted with an unsupported accusation, tries to prove his own innocence by collecting all the facts he can muster, instead of defying his accuser to prove the charge. Such a reply would be ineffective, and even rouse a strong suspicion of guilt by appearing too defensive. The attacked person has overlooked his strongest weapon of defence-the burden of proof. The problem is that the attacker falsely appears to have the weight of presumption on his side, to the extent that the underlying shift in the burden of proof has gone unnoticed (Walton 1993, p. 137).

In other words, the attacker succeeds in getting the attacked person to accommodate her-i.e., the attacker's - authority to perform binding presumptions; this accommodation, though unwarranted, is effective as a rhetorical trick that can be likened to Popperian conventionalist stratagems discussed in Sect. 3.1. The attacked person, then, should respond by blocking the unjust accommodation and thereby defusing the attacker presumption by showing that it is "null and void." (Austin 1975, p. 31; cf. Caponetto 2018).

Second, the notion of accommodation proves itself to be a useful tool for explaining the functioning of presumptions construed as constative illocutionary acts in BermejoLuque's (2016) sense. In "Being a Correct Presumption vs. Being Presumably the Case," she adopts Bach and Harnish's (1979) Gricean perspective on speech acts, the central tenet of which is that the force of an act is determined by the communicative intention with which it is made; more specifically, Bach and Harnish take communicative speech acts - that they contrast with conventional illocutions - to be Gricean acts of speaker meaning. According to Bach and Harnish, the point behind making a constative communicative illocutionary act is to "express the speaker's belief and [her] intention or desire that the hearer have or form a like belief;" (Bach and Harnish 1979: p. 41) they also stipulate that for a speaker to express propositional attitude $A$ in making an utterance is to reflexively-intend the hearer to get the utterance as reason to think that the speaker has attitude $A$. Viewed from the perspective of their taxonomy of illocutionary acts, then, presumptions in Bermejo-Luque's sense make up a subtype of constative acts: In presuming that $p$, the speaker expresses a complex propositional attitude that can be described as her deeming that it is reasonable to assume that $p$; for Bermejo-Luque, namely, "mental events of deeming it reasonable to assume that something is the case" (Bermejo-Luque 2016, p. 10) are mental counterparts of presumptions in the same manner as beliefs are mental counterparts of assertions. She claims that "presuming that $p$ is behaving so as to count as meaning that it is reasonable to assume that p;" (Ibid., p. 9) in other words, it is "contending that it is reasonable to behave as if $p$ were true," (Ibid., p. 10) where contending can be regarded as a type of constative illocutionary force in Bach and Harnish's sense.

The approach I adopt in this paper is Austinian, rather than Gricean; in other words, I assume that the force of an act depends on the effect its performance has on the social context, rather than on the communicative intention with which it is made (for a detailed discussion of the difference between Austinian and Gricean theories of 
speech acts, see Witek 2013b). As a result, I am reluctant to adopt Bermejo-Luque's perspective on presumptions; in particular, I do not share her idea that incorrect presumptions are still presumptions (for a discussion, see the introductory paragraphs of Sect. 3.) What is more, it seems to me that her implicitly, rather than explicitly held model of the dynamics of presumings assumes the Lewisian reductionist approach to accommodation. She claims that "[a]s a constative [or, more precisely, as an act of contending-M.W.], a presumption that $p$ will be semantically correct if and only if $p$ is a reasonable assumption indeed - that is, if it is reasonable to assume that $p$; much in the same way in which an assertion that $p$ is semantically correct if and only if $p$ is true." (Ibid., p. 10) In short, a presumption that $p$ requires, for its semantic correctness, that it is reasonable to assume that $p$. If issued with the required authority, then, the act under discussion produces its effect-i.e., it confers on the proposition that $p$ the presumptive status of being reasonably assumed-by following the Lewisian pattern (L): Provided certain conditions are met, it requires and thereby creates what it requires.

Finally, let us consider the following passage in which Corredor discusses dialogue (11):

To the extent that $B$ 's presumptive speech act is finally questioned and not agreed upon by $A$, it could be said to be a failed, infelicitous speech act. In terms of the Austinian approach, the lack of agreement in an informal, not institutionalized context (as is the case here imagined) determines that the utterance does not attain its (intended) conventional effect, namely, it does not acquire the force of a working presumption in the succeeding interaction. Yet, in order for $A$ to express her refusal, she has tacitly acknowledged that the speech act was a presumption (since she has assumed the burden of proof), though a defective one (given that the utterance was rejected as an unreasonable endorsement). This outcome, paradoxical as it may seem, is nevertheless standardly assumed as a fertile result of speech act theory. An utterance can be said to be a defective, flawed or infelicitous speech act, yet be recognized as a performed speech act (Corredor 2017, p. 586).

Viewed from the perspective of the model I have presented in Sect. 3, however, the above-mentioned appearance of paradox - that $B$ 's utterance of (11c) is a felicitous though defective presumption-can be easily removed. It suffices to note that the conversational move under discussion takes effect as a felicitous individual presumption but, at the same time, fails to get $A$ to endorse the opinion expressed by $B$; as a result, the conversational sequence it gives rise to fails to constitute a successful joint presumption. The shift in the burden of proof is achieved, but the proposition that $C$ is honest "does not acquire the force of a working presumption in the succeeding interaction:" It is not given the status of jointly recognized mutual endorsement. In short, the move made in uttering (11c) is a felicitous act of individual presumption and, at the same time, is defective as an attempt to initiate a conversational sequence constituting a felicitous act of joint presumption.

Acknowledgements The preparation of this work is supported by the National Science Centre, Poland, through research Grant No. 2015/19/B/HS1/03306. Earlier versions of this paper have been presented at 
the ArgLab Research Colloquium (Instituto de Filosofia da Nova, Universidade Nova de Lisboa, Lisbon, 5th March 2018), the workshop "Presupposition, Force and Social Norms" (University of Cambridge, 11th May 2018), and the workshop "Perspectives on Speech as Action" (Università degli Studi di Trieste, Trieste, 8-9 November 2018). I would like to thank the participants of these three meetings-in particular, Marcin Lewiński, Pedro Abreu, Erich Rast, and Dima Mohammed (Lisbon), Rae Langton, Kasia M. Jaszczolt, David Beaver, and Roberto Sileo (Cambridge), Marina Sbisà, Paolo Labinaz, Laura Caponetto, and Cristina Corredor (Trieste) — for their lively and productive discussions. I would also like to express my gratitude to two anonymous reviewers for their insightful comments and helpful suggestions on an earlier version of this paper.

Open Access This article is distributed under the terms of the Creative Commons Attribution 4.0 International License (http://creativecommons.org/licenses/by/4.0/), which permits unrestricted use, distribution, and reproduction in any medium, provided you give appropriate credit to the original author(s) and the source, provide a link to the Creative Commons license, and indicate if changes were made.

\section{References}

Austin, J. L. (1975). How to do things with words. Oxford: The Clarendon Press.

Bach, K., \& Harnish, R. M. (1979). Linguistic communication and speech acts. Cambridge, MA: MIT Press. Bermejo-Luque, L. (2016). Being a correct presumption vs. being presumably the case. Informal Logic, $36(1), 1-25$.

Budzyńska, K., \& Witek, M. (2014). Non-inferential aspects of Ad Hominem and Ad Baculum. Argumentation, 28, 301-315.

Caponetto, L. (2018). Undoing things with words. Synthese. https://doi.org/10.1007/s11229-018-1805-9.

Corredor, C. (2017). Presumptions in speech acts. Argumentation, 31, 573-589.

Freeman, J. B. (1996). Review of Plausible argument in everyday conversation, by D. Walton. Informal Logic, 18(2\&3), 288-298.

Gazdar, G. (1981). Speech act assignment. In A. K. Joshi, B. H. Webber, \& I. A. Sag (Eds.), Elements of discourse understanding (pp. 64-83). Cambridge: Cambridge University Press.

Godden, D. (2017). Presumption as a modal qualifier: Presumption, inference, and managing epistemic risk. Argumentation, 31, 485-511.

Godden, D., \& Walton, D. (2007). A theory of presumption for everyday argumentation. Pragmatics \& Cognition, 15(2), 313-346.

Green, M. (2009). Speech acts, the handicap principle and the expression of psychological states. Mind and Language, 24(2), 139-163.

Heal, J. (2013). Illocution, recognition and cooperation. Proceedings of the Aristotelian Society Supplementary, 87, 137-154.

Jaszczolt, K. M., \& Witek, M. (2018). Expressing the self: From types of de se to speech-act types. In M. Huang \& K. M. Jaszczolt (Eds.), Expressing the self. Cultural diversity and cognitive universals (pp. 187-221). Oxford: Oxford University Press.

Langton, R. (2015). How to get a norm from a speech act. The Amherst Lecture in Philosophy, 10, 1-33.

Langton, R. (2018). Blocking as counter-speech. In D. Fogal, D. W. Harris, \& M. Moss (Eds.), New work on speech acts (pp. 144-164). Oxford: Oxford University Press.

Lepore, E., \& Stone, M. (2015). Imagination and convention. Distinguishing grammar and inference in language. Oxford: Oxford University Press.

Lewiński, M. (2017). Argumentation theory without presumptions. Argumentation, 31, 591-613.

Lewis, D. (1970). General semantics. Synthese, 22(1-2), 18-67.

Lewis, D. (1979). Scorekeeping in a language game. Journal of Philosophical Logic, 8, 339-359.

McGowan, M. K. (2004). Conversational exercitives: Something else we do with our words. Linguistics and Philosophy, 27, 93-111.

McGowan, M. K. (2009). On pragmatics, exercitive speech acts, and pornography. Lodz Papers in Pragmatics, 5(1), 133-155.

Millikan, R. G. (2005). Language: A biological model. Oxford: Oxford University Press.

Popper, K. R. (1962). Conjectures and refutations. The growth of scientific knowledge. New York: Basic Books. 
Popper, K. R. (2005). The logic of scientific discovery. London: Routledge.

Putnam, H. (1981). Reason, truth and history. Cambridge: Cambridge University Press.

Roberts, C. (2015). Accommodation in a language game. In B. Loewer \& J. Schaffer (Eds.), The Blackwell companion to David Lewis (pp. 345-366). Oxford: Blackwell.

Sbisà, M. (1984). On illocutionary types. Journal of Pragmatics, 8, 93-112.

Sbisà, M. (1999). Ideology and the persuasive use of presupposition. In J. Verschueren (Ed.), Language and ideology: Selected papers from the 6th international pragmatics conference (Vol. I, pp. 492-509). Antwerp: International Pragmatics Association.

Sbisà, M. (2002). Speech acts in context. Language \& Communication, 22, 421-436.

Sbisà, M. (2007). How to read Austin. Pragmatics, 17(3), 461-473.

Sbisà, M. (2009). Uptake and conventionality in illocution. Lodz Papers in Pragmatics, 5(1), $33-52$.

Sbisà, M. (2013). Locution, illocution, perlocution. In M. Sbisà \& K. Turner (Eds.), Pragmatics of speech actions (pp. 25-76). Berlin: De Gruyter Mouton.

Sbisà, M. (2019). Varieties of speech act norms. In M. Witek \& I. Witczak-Plisiecka (Eds.), Normativity and variety of speech actions (pp. 23-50). Leiden: Brill. (Poznań Studies in the Philosophy of the Sciences and the Humanities, Vol. 112).

Searle, J. R. (1969). Speech acts. An essay in the philosophy of language. Cambridge: Cambridge University Press.

Searle, J. R. (1979). Expression and meaning. Cambridge: Cambridge University Press.

Searle, J. R. (1992). Conversation. In J. R. Searle, et al. (Eds.), (On) Searle on conversation (pp. 7-30). Amsterdam: John Benjamins Publishing Company.

Simons, M. (2003). Presupposition and accommodation. Understanding the Stalnakerian picture. Philosophical Studies, 112, 251-278.

Slobin, D. I. (1996). From "thought and language" to "thinking for speaking". In J. J. Gumperz \& S. C. Levinson (Eds.), Rethinking linguistic relativity (pp. 70-96). Cambridge: Cambridge University Press.

Stalnaker, R. (2002). Common ground. Linguistics and Philosophy, 25, 701-721.

Stalnaker, R. (2014). Context. Oxford: Oxford University Press.

Thomason, R. H. (1990). Accommodation, meaning and implicature. In P. R. Cohen, J. Morgan, \& M. E. Pollack (Eds.), Intentions in communication (pp. 325-363). Cambridge, MA: MIT Press.

Tomasello, M. (2014). A natural history of human thinking. Cambridge, MA: Harvard University Press.

Vanderveken, D. (1990). Meaning and speech acts. Cambridge: Cambridge University Press.

von Fintel, K. (2008). What is presupposition accommodation, again? Philosophical Perspectives, 22, $137-170$.

Walton, D. (1993). The speech-act of presumption. Pragmatics \& Cognition, 1, 125-148.

Witek, M. (2013a). How to establish authority with words: Imperative utterances and presupposition accommodation. In A. Brożek, J. Jadacki, \& B. Žarnic (Eds.), Theory of imperatives from different points of view (2) (pp. 145-157). Warszawa: Semper.

Witek, M. (2013b). Three approaches to the study of speech acts. Dialogue and Universalism, 23(1), $129-142$.

Witek, M. (2015a). An interactional account of illocutionary practice. Language Sciences, 47, 43-55.

Witek, M. (2015b). Linguistic underdeterminacy: A view from speech act theory. Journal of Pragmatics, $76,15-29$.

Witek, M. (2015c). Mechanisms of illocutionary games. Language \& Communication, 42, 11-22.

Witek, M. (2016). Convention and accommodation. Polish Journal of Philosophy, 10(1), 99-115.

Witek, M. (2019a). Accommodation in linguistic interaction. On the so-called triggering problem. In P. Stalmaszczyk (Ed.), Philosophical insights into pragmatics (pp. 163-191). Berlin: De Gruyter.

Witek, M. (2019b). Coordination and norms in illocutionary interaction. In M. Witek \& I. Witczak-Plisiecka (Eds.), Normativity and variety of speech actions (pp. 66-97). Leiden: Brill. (Poznań Studies in the Philosophy of the Sciences and the Humanities, Vol. 112).

Witek, M. (2019c). The expressive dimension and score-changing function of speech acts from the evolutionist point of view. Grazer Philosophische Studien, 96, 381-398.

Publisher's Note Springer Nature remains neutral with regard to jurisdictional claims in published maps and institutional affiliations. 